Illinois State University

ISU ReD: Research and eData

Theses and Dissertations

$12-1-2019$

\title{
Effects of Video Technology on Cooking Self-Efficacy
}

Zakary Kaesberg

Illinois State University, zakaesb@ilstu.edu

Follow this and additional works at: https://ir.library.illinoisstate.edu/etd

Part of the Human and Clinical Nutrition Commons

\section{Recommended Citation}

Kaesberg, Zakary, "Effects of Video Technology on Cooking Self-Efficacy" (2019). Theses and Dissertations. 1192.

https://ir.library.illinoisstate.edu/etd/1192

This Thesis is brought to you for free and open access by ISU ReD: Research and eData. It has been accepted for inclusion in Theses and Dissertations by an authorized administrator of ISU ReD: Research and eData. For more information, please contact ISUReD@ilstu.edu. 


\section{EFFECTS OF VIDEO TECHNOLOGY ON COOKING SELF-EFFICACY}

\section{ZAKARY KAESBERG}

66 Pages

College students, on average, have poor nutritional habits associated with increasing risk of obesity and chronic disease later in life. Today's average student has low self-efficacy for cooking meals in the home and thus, is highly dependent on convenience-type food items. A valuable technique for improving cooking skill in individuals is through the use of video technology to teach cooking. Undergraduate students are likely Millennials and prefer to use technology for learning purposes. The objective of this study was to test the effect of video technology on cooking self-efficacy in undergraduate college students living off-campus at a public Midwestern University. Two groups of undergraduate college students $(n=71)$ were assessed for baseline self-efficacy for cooking skill and number of meals cooked per week using an online survey. One group received five weeks of recipe cards and surveys assessing selfefficacy for cooking the meal and barriers to cooking in the home. The second group received five weeks of a recipe card and accompanying cooking video in addition to a survey assessing the same parameters. Participants were also surveyed at the end of the study to assess changes in cooking self-efficacy, number of meals cooker per week, and differences between groups. There were statistically significant improvements from pretest to posttest cooking self-efficacy scores

for participants but no statistically significant differences between pretest and posttest number of meals cooked per week $(\mathrm{p}>.05)$. There were no statistical differences between intervention groups ( $\mathrm{p}>.05)$. Conclusions of the study found students reported confidence in cooking skill, but 
lacked time and equipment associated with cooking healthy meals. Overall, the use of video technology was effective at improving self-efficacy for cooking if: 1) Meals are simple, short, and specific. 2) Recipe videos are short to maintain viewer attention.

KEYWORDS: college students; self-efficacy; cooking; video technology; culinary skills; health belief model 


\title{
EFFECTS OF VIDEO TECHNOLOGY ON COOKING SELF-EFFICACY
}

ZAKARY KAESBERG

\author{
A Thesis Submitted in Partial \\ Fulfillment of the Requirements \\ for the Degree of \\ MASTER OF SCIENCE \\ Department of Family and Consumer Sciences \\ ILLINOIS STATE UNIVERSITY
}


Copyright 2020 Zakary Kaesberg 


\title{
EFFECTS OF VIDEO TECHNOLOGY ON COOKING SELF-EFFICACY
}

\author{
ZAKARY KAESBERG
}

COMMITTEE MEMBERS:

Julie Schumacher, Chair

Amy Bardwell

Kerri Calvert 


\section{ACKNOWLEDGMENTS}

I would like to express my gratitude to Dr. Julie Schumacher who pushed me and supported me throughout my undergraduate and graduate study. She was also crucial to the idea of this project evolving into a thesis study. I would also like to give special thanks to Dr. Amy Bardwell and Kerri Calvert for being my supportive committee members while I finished my thesis study. Lastly to those close to me, thank you for always being there for me and giving me an area to ventilate and work through challenges.

Z. K. 


\section{CONTENTS}

Page

ACKNOWLEDGMENTS

TABLES

FIGURES

CHAPTER I: INTRODUCTION 1

$\begin{array}{ll}\text { Methods } & 4\end{array}$

Sample Recruitment and Selection $\quad 4$

$\begin{array}{ll}\text { Participants } & 5\end{array}$

Randomization $\quad 5$

Pre/Post Study Survey $\quad 5$

$\begin{array}{ll}\text { Study Design } & 6\end{array}$

$\begin{array}{ll}\text { Statistical Analysis } & 9\end{array}$

$\begin{array}{ll}\text { Results } & 10\end{array}$

$\begin{array}{ll}\text { Sample Self-Efficacy Pretest and Posttest } & 10\end{array}$

Sample Pretest and Posttest Number of Meals Cooked per Week 10

Group Comparison Pretest and Posttest Self-Efficacy 11

Group Comparison Weeks 1-5 Self-Efficacy 13

Qualitative Barriers to Cooking Meals Weeks 1-5 14

$\begin{array}{ll}\text { Discussion } & 21\end{array}$

CHAPTER II: EXTENDED REVIEW OF THE LITERATURE 28

$\begin{array}{ll}\text { Undergraduate College Students } & 28\end{array}$

$\begin{array}{ll}\text { Nutrition Education } & 30\end{array}$ 
Cooking Skill and Health

Cost of Cooking at Home

Health Belief Model (HBM)

Self-Efficacy

Technology

REFERENCES

APPENDIX A: INFORMED CONSENT 


\section{TABLES}

Table

Page

1. Mean Self-Efficacy Scores for Pretest and Posttest Survey 12

2. Sample Percentage Pretest and Posttest Number of Meals Cooked Per Week 13

3. Effect of Time on Participant Pretest and Posttest Self-Efficacy Scores 17

4. Group Comparison of Self-Efficacy Pretest and Posttest Changes 18

5. Mean Self-Efficacy Scores for Weeks 1-5 19

6. Participant Self-Reported Ability and Plans for Preparing Meals 20 


\section{FIGURES}

Figure $\quad$ Page

$\begin{array}{ll}\text { 1. Rainbow salsa recipe } & 7\end{array}$

$\begin{array}{ll}\text { 2. Vegetarian chili recipe } & 7\end{array}$

3. Simple colorful salad recipe $r$

4. Zucchini banana bread recipe $\quad 8$

5. No-mayo chicken salad recipe $\quad 9$ 


\section{CHAPTER I: INTRODUCTION}

Undergraduate college students gain an exponential amount of independence in their first years at school. For many of these students, their eating habits center primarily on dining hall meals that require little to no actual cooking or preparation from the consumer (Peterson, Duncan, Null, Roth, \& Gill, 2010). However, with rising levels of attendance to colleges and universities in the United States, there is a greater need for more apartment or residence type housing for undergraduate students (National Center for Health Statistics [NCHS], 2018; Ong, Petrova, \& Spieler, 2013). For many students, living off-campus is their first exposure to preparing meals in-home for themselves.

The American College Health Association's Spring 2019 Undergraduate Report found that only $3.6 \%$ of college students consumed five or more servings of fruits and vegetables per day (American College Health Association [ACHA], 2019). This means that only 3.6\% of college students met the United States Department of Agriculture's 2015-2020 Dietary Guidelines recommended for adults 19-30 years old (United States Department of Agriculture [USDA], 2015). Additionally, Huang et al. (2003), found that only $32.9 \%$ of college students were consuming more than 20 grams of fiber per day, compared to the current Dietary Guidelines for Americans of 28 grams per day for women and 33.6 grams per day for men between the ages of 19-30 years old (USDA, 2015).

As enrollment in colleges and universities has increased, on-campus housing has not met the demand of all enrolling students (United States Department of Housing and Urban Development, 2015). This has caused many more colleges and universities to offer off-campus housing for students. According to the United States Census Bureau from 2009-2011, 51.8\% of students living off campus and not with relatives had incomes below the poverty level (United 
States Department of Housing and Urban Development, 2015). Relatedly, these same students are placed at a lower food security (United States Department of Housing and Urban Development, 2015). Additionally, Small, Bailey-Davis, Morgan, and Maggs (2012) found that students living off-campus consumed fruits and vegetables $7 \%$ less and were physically active $21 \%$ fewer days compared to students living on campus.

The Health Belief Model can help explain the low adherence to dietary guidelines in college students. The Health Belief Model is based on the understanding that a person will take a health related action if that person 1) feels that a negative health condition can be avoided from action, 2) has a positive expectation that by taking action, they will avoid a negative health condition, and 3) they believe they can successfully perform a recommended health action (Jones et al., 2015).

Teaching methods differ across generations. Today's average undergraduate student is more than likely born between 1980-2000, placing them in the category known as the Millennial generation (Raines, 2003). Since Millennials have aged with always having technology available, they are known as the "wired generation" that may learn more effectively when given interactive technology. Technology in today's society is an essential tool for keeping the public engaged and plays a significant role in education due to its integration into traditional classes. The increasing availability of technology in society has provided an opportunity for teaching new skills to many viewers at a time.

Video technology in particular for teaching has been found to improve social interaction, provide an individual learning environment, be a simple delivery system, be highly portable, and give learners the ability to pause and rewind their learning (Beheshiti, Taspolat, Kaya, \& Sapanca, 2018). In a study comparing methods of teaching cooking skills, focus groups found 
that video technology was the most effective method for teaching college students cooking skills (Surgenor et al., 2017). However, this study failed to measure how the students' perceived ability to cook meals on their own improved as a result.

The purpose of this study was to test video technology's role in improving the selfefficacy for cooking in undergraduate college students living off-campus at a public Midwestern University. Self-efficacy refers to one's belief that they are capable of carrying out the actions necessary for completing a specific behavior (Maddux, 1995). The independent variables in this study were the intervention of a weekly healthy recipe card and a cooking video filmed from the cook's point of view. The dependent variables of this study were the effects of the recipe interventions on immediate post-video self-efficacy and post-study self-efficacy, as well as changes in average number of meals cooked in the home per week as a result of this study. Research questions for this study were as follows: 1.) Will long-term self-efficacy for cooking improve when participants are given a video and recipe card or recipe card only? 2.) Will the interventions have a positive effect on cooking self-efficacy each week? and 3.) Will the average number of meals cooked in the home each week improve after five weeks of intervention? This study is significant for health professionals and educators because video technology can potentially be another resource for improving student health and wellness on a larger scale. 


\section{Methods}

\section{Sample Recruitment and Selection}

Students who elected to receive research emails were recruited to the study via studentemails sent by Illinois State University's Administrative Technologies (Appendix A). Interested participants were able to access the online survey by following the link provided in the recruitment email. Sample recruitment and selection of participants was carried out taking into consideration some inclusive criteria: (1) being between 18-25 years-old; (2) living in apartment or house with full kitchen access; (3) not living with parent or guardian(s); and (4) must hold undergraduate status at Illinois State University. The 18-25 age group and academic status was chosen to accurately represent the average undergraduate student. Apartment or house with kitchen access was a mandatory criterion to ensure participants have access to a kitchen for preparing recipes throughout the intervention. A criterion for not living with a parent or guardian was chosen so participants would have full responsibility for seeking out meals. Student exclusion criteria for the study was (1) experience as a trained chef or have worked in a kitchen; (2) vegan, vegetarian, specific dietary preferences, or have food allergies/intolerances; or (3) having children. Experience as a trained chef was an exclusionary criteria to represent the average undergraduate student who is not trained in culinary skills. Participants were required to be available to consider trying recipes without dietary preferences or presence of food allergies/intolerances hindering responses. Lastly, having children was considered exclusionary criteria to accurately represent the average undergraduate student. Participants that were found eligible and completed the study earned a $10 \$$ gift card as an incentive if they chose. This study was deemed exempt from the Illinois State University Institutional Review Board. 


\section{Participants}

The final sample of 71 students consisted of both males (14.1\%) and females $(85.9 \%)$. The majority of students self-reported living in an apartment with kitchen access $(87.3 \%)$ with the rest of the sample living in a home (12.7\%). Of the sample, $98.6 \%$ were considered legally single with $1.4 \%$ of students being legally married. Age groups of the sample consisted of $5.6 \%$ between the ages of $18-19,73.3 \%$ between $20-21$ years old, and $21.1 \%$ between $22-23$ years old. For university status, only $1.4 \%$ of students were Freshman, $2.8 \%$ Sophomores, $56.4 \%$ Juniors, and $39.4 \%$ Seniors.

\section{Randomization}

Participants were randomly assigned into two groups to ensure homogenization and a similar number of participants in each of the groups. Participants' random order to groups 1 or 2 was determined using the online software Research Randomizer (https://www.randomizer.org/) and were five times randomized. Students were not notified as to which intervention they received and were not informed on the other group's intervention.

\section{Pre/Post Study Survey}

Pre-study surveys were given to participants a week prior to the study's initiation via a link within the recruitment email. The link took participants to the informed consent. Upon completion and agreement to participate, they were directed to the pretest survey (Appendix B). A majority of the survey evaluated participants on their eligibility for the study based on the inclusion criteria. Students that were found ineligible for the study based on their answers were automatically directed to the end of the survey and thanked for their participation. Students that were found to be eligible for the study continued to complete questions related to their selfefficacy for cooking. A five-point Likert scale (1=not at all confident, 5=extremely confident) 
was used to measure students' self-reported ability and comfort with cooking at home, following a written recipe, preparing dinner from items already in the kitchen, cooking for scratch, and cooking healthy meals in the home. Additionally, an identical five-point Likert scale was used to measure students' self-efficacy related to various cooking techniques such as boiling, simmering, sautéing, stir-frying, grilling, baking, roasting, or microwaving foods. The end of the survey questioned participants on demographic information related to age, gender identity, marital status, and whether or not they had children.

\section{Study Design}

This study was a cross-sectional survey. Students who completed the pretest survey and were found to be eligible were randomized into two groups. Both groups received five weeks of a specific intervention. One group was emailed each week with a digital recipe card (Figure 1-5) created by the author displaying an ingredient list, procedures for completing the recipe, and a colored image of the finished dish. The second group was emailed each week with a digital recipe card identical to the first group, but in addition they received a four to five minute cooking video for that recipe filmed by the primary researcher's first person point of view. Both groups were asked to complete a required short survey (Appendix C) each week after viewing the resource. Weekly surveys were required in order to receive the $\$ 10$ gift card for the study. The weekly surveys used a five-point Likert scale to evaluate perceived confidence for cooking that meal at home and performing those specific cooking techniques. The survey also gave the option for participants to add any perceived barriers they would encounter when trying to prepare that meal. Lastly, the weekly survey asked participants if they planned to try completing that recipe. After the five-week intervention, students completed a post-study survey identical to the pre 
study (Appendix B). Compensation was provided to participants a week after they completed their post-study survey.

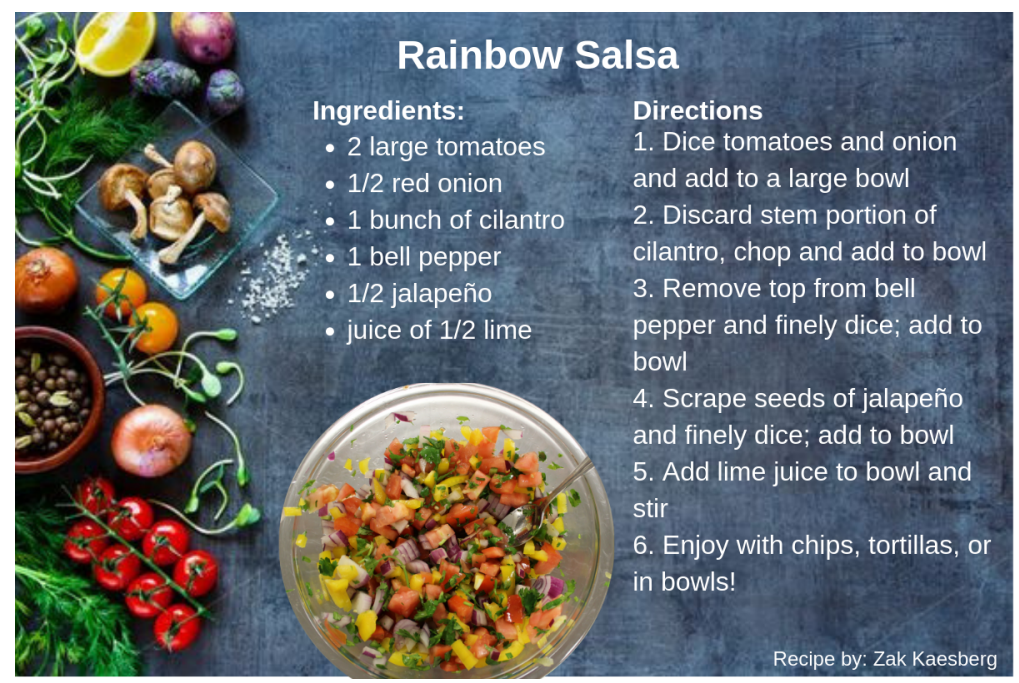

Figure 1. Rainbow salsa recipe.

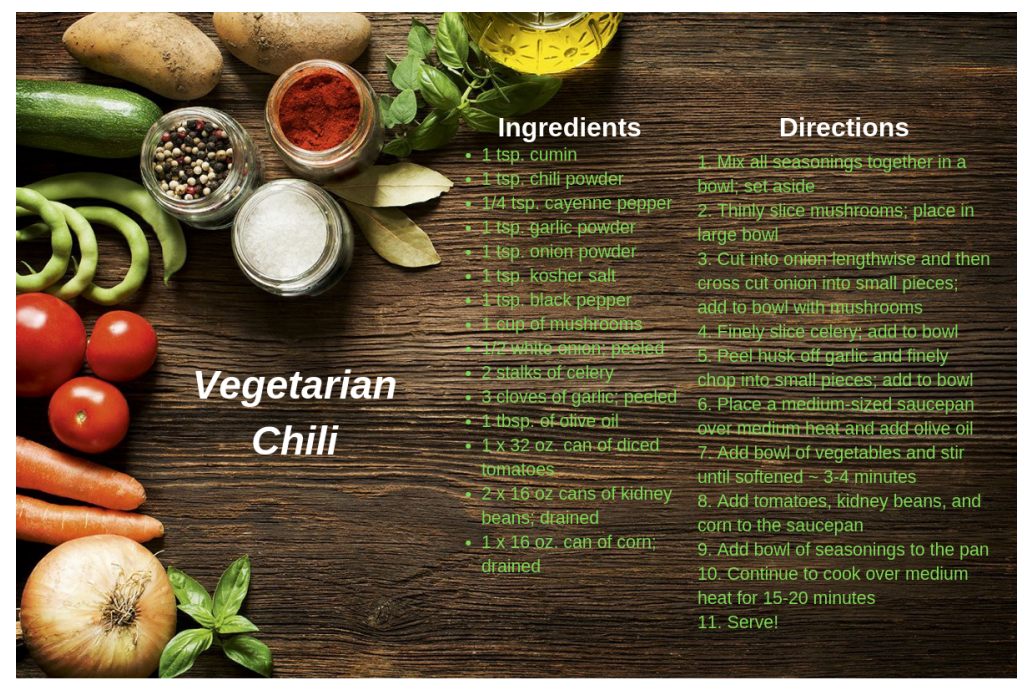

Figure 2. Vegetarian chili recipe. 


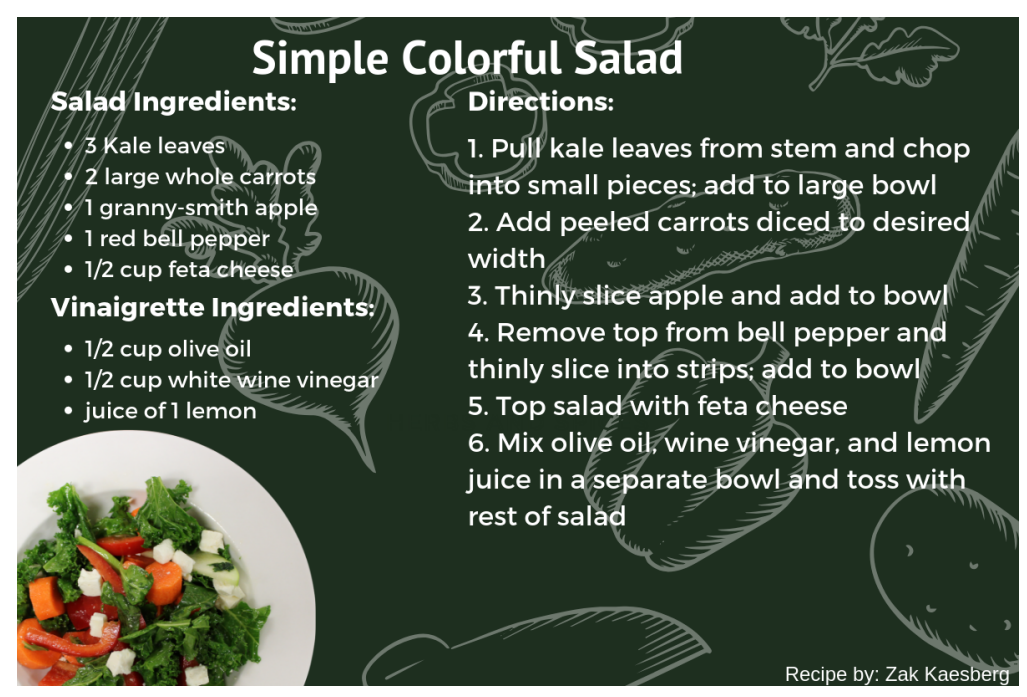

Figure 3. Simple colorful salad recipe.

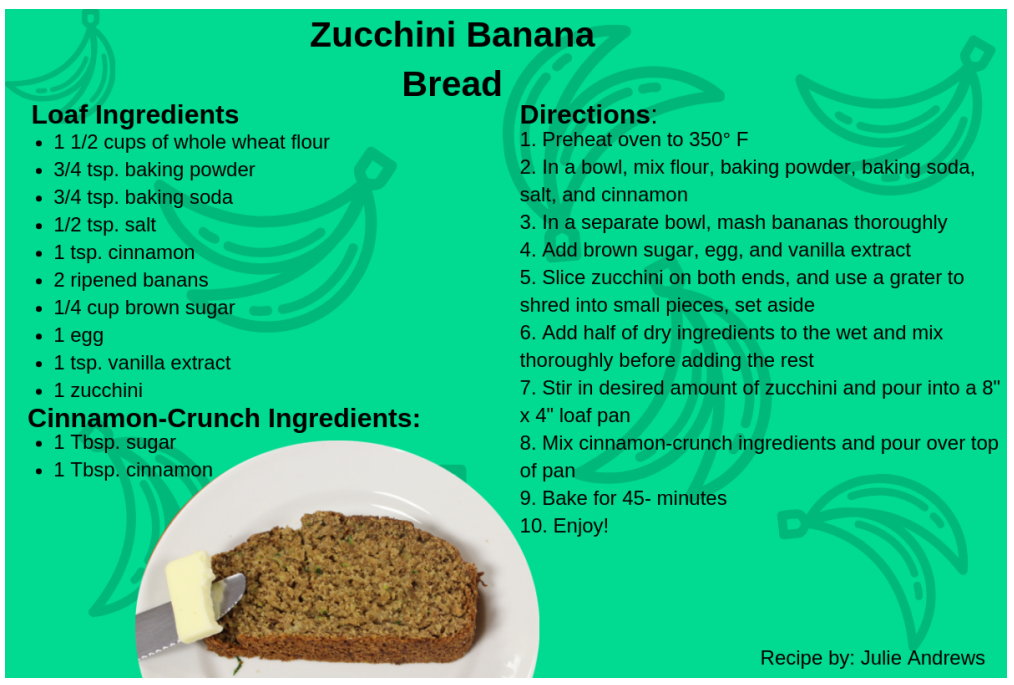

Figure 4. Zucchini banana bread recipe. 


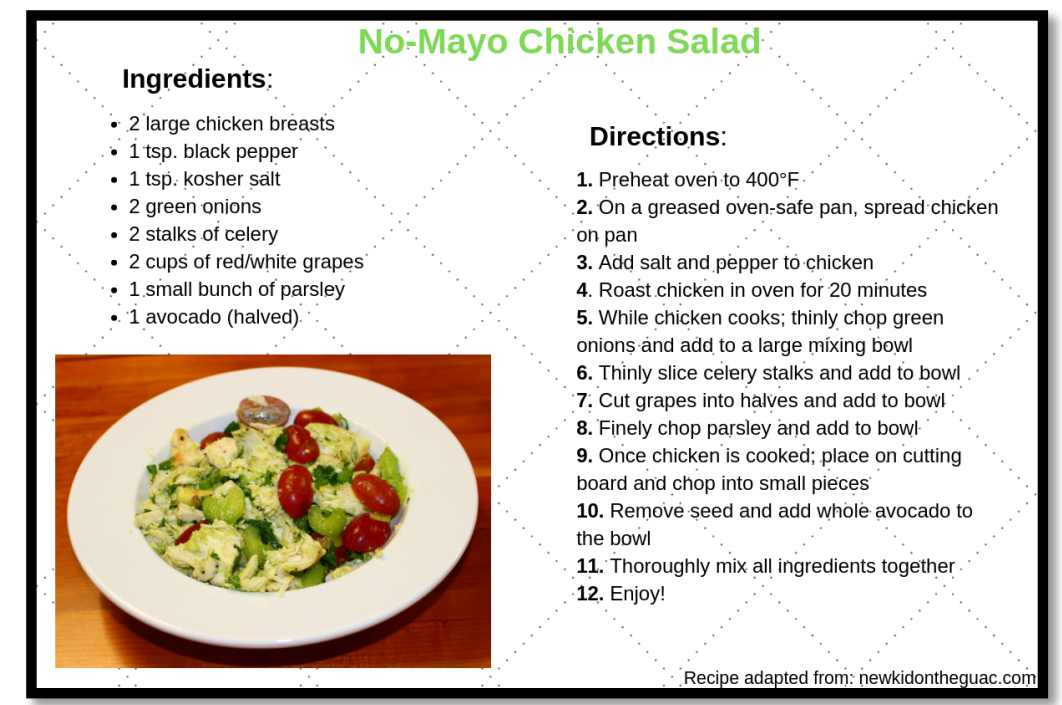

Figure 5. No-mayo chicken salad recipe.

\section{Statistical Analysis}

All data were analyzed in IBM SPSS 24.0. Descriptive statistics were computed to characterize the sample. Demographic data were analyzed per gender, age group, university status, and marital status. All statistical significance was reported at $p \leq .05$.

Pre and post-study self-efficacy scores were analyzed using a mixed between-within ANOVA to compare groups given that this type of analysis uses variables measured several times to determine the effect of an intervention. A Wilcoxon Signed Rank Test was used to compare differences between pretest and posttest scores for Number of meals cooked per week. A mixed between-within ANOVA was also used to examine the impact of recipe card or video and recipe card conditions on cooking self-efficacy across five time periods during the study (Week 1-5). Additionally, a paired samples t-test was used to analyze sample changes in the self-efficacy from pretest to posttest. Qualitative data from participants about barriers to cooking a meal at home was analyzed for grouping of responses. 


\section{Results}

\section{Sample Self-Efficacy Pretest and Posttest}

Descriptive statistics were calculated for the pretest and posttest scores of the sample. Pretest and posttest self-efficacy scores for Cooking at home, Following a written recipe, Preparing dinner from items already in the kitchen, Cooking from scratch, Planning and cooking healthy meals, Boiling, Simmering, Sautéing, Stir-frying, Grilling, Baking, Roasting, and Microwaving are reported in Table 1. All mean self-efficacy scores improved from pretest to posttest with an average improvement for all variables of 0.40 .

Next a paired samples t-test was performed to determine if there was a statistically significant difference between the mean pretest and posttest scores for each variable. There was a statistically significant difference between pretest and posttest scores for Cooking at home $(\mathrm{t}=6.05, \mathrm{p} \leq .001)$, Following a written recipe $(\mathrm{t}=4.35, \mathrm{p} \leq .001)$, Preparing dinner from items already in the kitchen $(\mathrm{t}=3.90, \mathrm{p} \leq .001)$, Cooking from scratch $(\mathrm{t}=4.97, \mathrm{p} \leq .001)$, Planning and cooking healthy meals $(t=5.54, p \leq .001)$, Simmering $(t=3.374, p \leq .001)$, Sautéing $(t=4.29, p \leq$ $.001)$, Stir-frying $(\mathrm{t}=4.73, \mathrm{p} \leq .001)$, Grilling $(\mathrm{t}=3.120, \mathrm{p}=.003)$, Baking $(\mathrm{t}=3.82, \mathrm{p} \leq .001)$, Roasting ( $\mathrm{t}=4.34, \mathrm{p} \leq .001)$, and Microwaving $(\mathrm{t}=2.44, \mathrm{p}=.017)$. There was not a statistically significant difference between pretest and posttest mean scores for Boiling $(t=1.297, \mathrm{p}=.199)$.

\section{Sample Pretest and Posttest Number of Meals Cooked per Week}

Descriptive statistics were calculated for pretest and posttest scores for Number of meals cooked in the home per week. This variable was represented on a scale of number of meals cooked per week in the home ( $1=0-2$ meals/week, $2=3-5$ meals $/$ week, $3=6-8$ meals $/$ week, $4=9-11$ meals/week, 5=12-14 meals/week, $6=15+$ meals/week). Frequency tables computed to characterize the sample's pretest and posttest numbers of meals cooked per week are listed in 
Table 2. Pretest categories of number of meals cooked were as follows: 7\% cooked 0-2 meals per week, 32.4\% cooked 3-5 meals per week, 26.8\% cooked 6-8 meals per week, $14.1 \%$ cooked 9-11 meals per week, $12.7 \%$ cooked $12-14$ meals per week, and $7 \%$ cooked 15 or more meals per week. Posttest categories of number of meals cooked were as follows: $11.3 \%$ cooked 0-2 meals per week, 33.8\% cooked 3-5 meals per week, 19.7\% cooked 6-8 meals per week, 19.7\% cooked 9-11 meals per week, 8.5\% cooked 12-14 meals per week, and 7\% cooked 15 or more meals per week.

Next a related samples Wilcoxon Signed Rank Test was used to compare differences between pretest and posttest scores for Number of meals cooked per week. A Wilcoxon Signed Rank Test is used to compare two samples on repeated measures (pretest and posttest) of ordinal variables. Results of the Wilcoxon test found there was not a statistically significant difference between pretest and posttest scores for Number of meals cooked per week $(p=.345)$.

\section{Group Comparison Pretest and Posttest Self-Efficacy}

A mixed between-within subjects ANOVA test was conducted to assess the impact of two different interventions (Recipe card, Video and Recipe Card) on participants' self-efficacy scores across two time periods (pretest and posttest). Interactions between main effects for time, and main effects comparing the two types of interventions are reported in Tables 3 and 4 . There was a statistically significant main effect for time for variables Cooking at home, Following a written recipe, Preparing dinner from items already in the kitchen, Cooking from scratch, Planning and cooking healthy meals, Simmering, Sautéing, Stir-frying, Grilling, Baking, Roasting, and Microwaving. The main effect comparing the two types of interventions was not statistically significant for the self-efficacy variables. 
Table 1

Mean Self-Efficacy Scores for Pretest and Posttest Survey

\begin{tabular}{lll}
\hline Variable & Pretest & Posttest \\
\hline Cooking at Home & 3.52 & $4.10^{*}$ \\
Following a Written Recipe & 4.18 & $4.49^{*}$ \\
Preparing Dinner From Items Already in the Kitchen & 3.66 & $4.06^{*}$ \\
Cooking From Scratch & 2.94 & $3.48^{*}$ \\
Planning and Cooking Healthy Meals & 3.08 & $3.65^{*}$ \\
Boiling & 4.70 & 4.77 \\
Simmering & 3.80 & $4.14^{*}$ \\
Sautéing & 3.27 & $3.76^{*}$ \\
Stir-Frying & 2.83 & $3.37^{*}$ \\
Grilling & 2.82 & $3.18^{*}$ \\
Baking & 4.10 & $4.45^{*}$ \\
Roasting & 2.80 & $3.31^{*}$ \\
Microwaving & 4.80 & $4.94^{*}$ \\
\hline
\end{tabular}

Note. $(1=$ Not at all Confident $)(2=$ Not so Confident $)(3=$ Somewhat Confident $)$

(4=Very Confident) $(5=$ Extremely Confident $)$

$* p \leq .05$

Next a related samples Wilcoxon Signed Rank Test was used to compare differences between pretest and posttest scores for Number of meals cooked per week. A Wilcoxon Signed Rank Test is used to compare two samples on repeated measures (pretest and posttest) of ordinal 
variables. Results of the Wilcoxon test found there was not a statistically significant difference between pretest and posttest scores for Number of meals cooked per week $(\mathrm{p}=.345)$.

Table 2

Sample Percentage Pretest and Posttest Number of Meals Cooked Per Week

\begin{tabular}{lcc}
\hline Category & Pretest & Posttest \\
\hline 0-2 Meals per Week & $7 \%$ & $11.30 \%$ \\
3-5 Meals per Week & $32.40 \%$ & $33.80 \%$ \\
6-8 Meals per Week & $26.80 \%$ & $19.70 \%$ \\
9-11 Meals per Week & $14.10 \%$ & $19.70 \%$ \\
12-14 Meals per Week & $12.70 \%$ & $8.50 \%$ \\
15+ Meals per Week & $7 \%$ & $7 \%$ \\
\hline
\end{tabular}

\section{Group Comparison Weeks 1-5 Self-Efficacy}

A mixed between-within subjects ANOVA was conducted to compare the impact of the two different resource interventions (Recipe Card, Video and Recipe Card) on participants' Confidence in cooking that week's meal at home as well as Performing the cooking techniques from that week across five time periods (Week 1-5). Descriptive statistics for Confidence in cooking that week's meal at home as well as Performing the cooking techniques from that week are reported in Table 5. Multivariate tests and tests of between-within subjects were conducted for the sample. There was a statistically significant effect for time throughout weeks one through five for Cooking the meal at home Wilks' Lambda $=.74, \mathrm{~F}(4,66)=5.73, \mathrm{p}=.001$, partial eta squared $=.26$ and Performing the cooking techniques Wilks' Lambda $=.79, \mathrm{~F}(4,66)=4.48, \mathrm{p}=.003$, partial eta squared $=.214$. The main effect from the analysis found there was not statistically 
significant difference between resource groups for Cooking the meal at home $F(1,69)=.15$, $\mathrm{p}=.697$, partial eta squared $=.00$ and Performing the cooking techniques $\mathrm{F}(1,69)=.11, \mathrm{p}=.742$, partial eta squared $=.00$ in weeks one through five. Frequency values for participant self-reported Ability to complete the cooking techniques and Plans to try completing the recipes at home are reported in Table 6 .

\section{Qualitative Barriers to Cooking Meals Weeks 1-5}

Two researchers cooperated on the analysis of qualitative data. Participants were prompted with the weekly question "Do you perceive any barriers to preparing this meal at home?" If they responded yes, they were asked to list out the barriers to completing that meal. Data was collected each week of the intervention and qualitative grouping of barriers was conducted to organize sample responses.

Disliking ingredients or meal. Respondents frequently cited disliking ingredients or meals as a barrier to cooking the meal at home. Week 1 was a salsa recipe and several participants reported, "I do not like salsa" or "I do not like the ingredients." Week 3's recipe consisted of a kale-based salad. Four participants reported disliking the taste of kale or offering to use another cruciferous vegetable as a substitute. Week 5's recipe was an avocado-based chicken salad. One participant stated, "I do not like salad" one participant stated, "I would not use grapes" and one participant said, "I do not think it sounds very good."

Cost. Cost was a significant barrier for not completing a meal as many students are on a budget. The primary researcher prepared each meal of two to four servings on a budget of $\$ 20$ or less per meal. Week 2's recipe was a vegetarian chili recipe. This recipe consisted of about five different spices and several canned items. All five respondents from the week cited "having to buy so many ingredients" as a barrier to preparing the meal. Barriers from Week 3's recipe cited 
"the cost of product" as a barrier for preparing the meal. Week 4's recipe of zucchini banana bread only had one respondent who cited cost of ingredients as a barrier. And Week 5's recipe had one respondent that stated, "avocado is expensive."

Time and shopping. Time and transportation were frequent barriers due to not all students having a car or dependable form of transportation. Week 1's cited barriers were "It takes too long to dice several items" and two respondents who stated "need to grocery shop first" and “I don't currently have all the ingredients at my apartment." Week 2 had one response stating, "having all the ingredients on hand" as a barrier. Week 4 had one response stating "too many dishes to do afterwards" which is a viable concern for a student.

Inconvenience. Several participants stated that buying the food items was inconvenient because they don't usually purchase the items. Week 1 respondents stated "I do not usually buy tomatoes or bell peppers", "Procuring ingredients (like peppers) in winter", and "Making it for one person, I do not eat leftovers" as barriers. Week 2 had one respondent who stated, "I do not usually buy celery or corn." Week 4 respondents stated, "I do not buy zucchini, not too inclined to eat baked goods" and "my kitchen is too small to bake" as barriers.

Cooking skills. Intervention received was included as a factor in the analysis cooking skill as a barrier. Week 1 respondents who only received the recipe card stated, "how to cut jalapenos, what does a bunch of cilantro meal" and "cutting peppers is a little tricky for me because I do not do it very often." No video intervention respondents cited this as a barrier. The single barrier from Week 2 was from a recipe card respondent who stated, "cooking over heat without burning" as a barrier. Week 4 had a single response from a recipe card respondent who said, "I am not great at baking things." Week 5 had two responses. A response from a recipe card participant who said, "avocado is hard to prepare" and a video participant who stated, "how to 
roast chicken" as a barrier. Week 5's cooking video demonstrated how to roast chicken breasts for the recipe.

Allergies and food intolerances. Participants with allergies and food intolerances such as gluten intolerance or allergy to nightshade vegetables frequently cited meals that could not be prepared. One participant with an allergy to nightshade vegetables (tomatoes, eggplant, paprika, cayenne pepper, bell pepper) stated their allergy as a barrier for two out of five weeks. Week 4's baking recipe had three respondents that cited gluten (a protein of wheat) intolerance or glutenfree as a barrier for completing the recipe. Two responses included, "Cannot eat gluten, would substituted for rice flour", and one response said, "I am gluten-free and would have to make substitutions to this to make it gluten-free." It should be noted that the last response does not specify if the participant is gluten-free by choice or due to gluten intolerance.

Equipment. The recipes to cite equipment or utensils as a barrier to completing the recipe were zucchini banana bread in Week 4 and no-mayo chicken salad in Week 5. The Week 4 recipe calls for use of a grater to finely shred the zucchini and to mash bananas for mixing into a batter. Eight respondents stated not having a grater as a barrier. One respondent said, "I do not have a masher tool" and two respondents said, "I do not own a bread pan". There was one respondent for Week 5 that said, "my oven is currently broken" as a barrier. 
Table 3

Effect of Time on Participant Pretest and Posttest Self-Efficacy Scores

\begin{tabular}{|c|c|c|c|}
\hline Variable & Wilks' & $\mathrm{p}$ & Partial Eta \\
\hline & Lambda & & Squared \\
\hline Cooking at Home & 0.67 & $0.00 *$ & 0.35 \\
\hline Following a Written Recipe & 0.78 & $0.00 *$ & 0.22 \\
\hline Preparing Dinner From Items Already in the Kitchen & 0.82 & $0.00 *$ & 0.18 \\
\hline Cooking From Scratch & 0.74 & $0.00 *$ & 0.26 \\
\hline Planning and Cooking Healthy Meals & 0.69 & $0.00 *$ & 0.31 \\
\hline Boiling & 0.98 & 0.20 & 0.02 \\
\hline Simmering & 0.86 & $0.00^{*}$ & 0.14 \\
\hline Sautéing & 0.79 & $0.00 *$ & 0.21 \\
\hline Stir-Frying & 0.76 & $0.00 *$ & 0.24 \\
\hline Grilling & 0.88 & $0.00 *$ & 0.12 \\
\hline Baking & 0.82 & $0.00 *$ & 0.18 \\
\hline Roasting & 0.78 & $0.00 *$ & 0.22 \\
\hline Microwaving & 0.92 & $0.02 *$ & 0.08 \\
\hline
\end{tabular}

Note.

$* p \leq .05$ 
Table 4

Group Comparison of Self-Efficacy Pretest and Posttest Changes

\begin{tabular}{|c|c|c|c|}
\hline Variable & F Value & $\mathrm{p}$ & $\begin{array}{c}\text { Partial Eta } \\
\text { Squared }\end{array}$ \\
\hline Cooking at Home & 0.13 & 0.715 & 0.35 \\
\hline Following a Written Recipe & 0.74 & 0.398 & 0.01 \\
\hline Preparing Dinner From Items Already in the Kitchen & 0.00 & 0.984 & 0.00 \\
\hline Cooking From Scratch & 0.17 & 0.681 & 0.00 \\
\hline Planning and Cooking Healthy Meals & 0.12 & 0.729 & 0.00 \\
\hline Boiling & 2.23 & 0.140 & 0.03 \\
\hline Simmering & 0.07 & 0.794 & 0.00 \\
\hline Sautéing & 0.27 & 0.607 & 0.00 \\
\hline Stir-Frying & 0.29 & 0.589 & 0.00 \\
\hline Grilling & 0.16 & 0.689 & 0.00 \\
\hline Baking & 0.04 & 0.844 & 0.00 \\
\hline Roasting & 3.05 & 0.085 & 0.04 \\
\hline Microwaving & 0.83 & 0.365 & 0.01 \\
\hline
\end{tabular}

Note.

$* p \leq .05$ 
Table 5

Mean Self-Efficacy Scores for Weeks 1-5

\begin{tabular}{lll}
\hline Week/Dish & Variable & Mean
\end{tabular}

Week 1

Homemade Rainbow Salsa

Cooking This Meal at Home

4.46

Performing These Cooking Techniques

4.28

Week 2

Vegetarian Chili

Cooking This Meal at Home

Performing These Cooking Techniques

4.10

Week 3

Salad With Homemade Vinaigrette

Cooking This Meal at Home

Performing These Cooking Techniques

4.56

Week 4

Zucchini Banana Bread

Cooking This Meal at Home

Performing These Cooking Techniques

Week 5

No-Mayo Chicken Salad

Cooking This Meal at Home

Performing These Cooking Techniques

Note. $(1=$ Not at all Confident)( $2=$ Not so Confident) $(3=$ Somewhat Confident)( $4=$ Very

Confident $)(5=$ Extremely Confident $)$ 
Table 6

Participant Self-Reported Ability and Plans for Preparing Meals

\begin{tabular}{llll}
\hline Week Variable & Yes & No
\end{tabular}

Week 1

Do you have the Ability to Complete These Techniques $\quad 94.40 \% \quad 5.60 \%$

Will you Plan to try Completing This Recipe $\quad 63.40 \% \quad 36.60 \%$

Week 2

Do you have the Ability to Complete These Techniques $\quad 98.60 \% \quad 1.40 \%$

Will you Plan to try Completing This Recipe $\quad 45.10 \% \quad 54.90 \%$

Week 3

Do you have the Ability to Complete These Techniques $\quad 100.00 \% \quad 0.00 \%$

Will you Plan to try Completing This Recipe $\quad 45.10 \% \quad 54.90 \%$

Week 4

Do you have the Ability to Complete These Techniques $\quad 97.20 \% \quad 2.80 \%$

Will you Plan to try Completing This Recipe $\quad 71.80 \% \quad 28.20 \%$

Week 5

Do you have the Ability to Complete These Techniques $\quad 97.20 \% \quad 2.80 \%$

Will you Plan to try Completing This Recipe $\quad 49.30 \% \quad 50.70 \%$ 


\section{Discussion}

Low cooking frequency in the home is associated with a higher rate of consuming caloric-dense fast or takeaway foods. College students living in off-campus housing have access to a kitchen but lack the skills to prepare their own meals so they rely on fast food or takeaway items. This dependence on high calorie processed food items is a potential explanation for rising rates of obesity and chronic disease in students later in life. College students are dependent on these foods because they lack the skill and self-efficacy for cooking at home so instead rely on the most convenient option.

Today's average college student has technology deeply ingrained in their social and educational life. Video technology has been used on several platforms to teach individuals with access to technology how to complete tasks and skills themselves. Video modeling (VM), the act of demonstrating a skill being performed first hand, is a beneficial use of technology to assist viewers. Interventions aimed at improving cooking skill have used technology and in-person activities to improve ability and skill for cooking techniques. However, few studies have compared the effect of video technology on self-efficacy and cooking frequency in college students.

Results from the paired samples t-test determined there was a statistically significant difference between mean scores for self-efficacy variables between pretest and posttest for the entire sample. Variables Cooking at home, Following a written recipe, Preparing dinner from items already in the kitchen, Cooking from scratch, Planning and cooking healthy meals, Simmering, Sautéing, Stir-frying, Grilling, Baking, Roasting, and Microwaving were statistically significant and Boiling was not a statistically significant result. A probable reason for students improved self-efficacy was that they had the opportunity to learn the verbiage for these 
techniques throughout the study and were given instruction on how to perform them. Boiling was the only variable that did not have a statistically significant result. This could likely be due to the fact that boiling is a very simple task that many students have likely performed before, therefore, they did not feel like their self-efficacy for the technique improved.

Results from the Wilcoxon Test found that Number of meals cooked per week was not statistically significant between pretest and posttest. Results from the weekly qualitative prompt may provide an explanation for the result. Time and transportation were frequently reported barriers to preparing meals every week by college students. While this study provides a learning tool for improving cooking skill it cannot assist with barriers such as transportation, time, and cost. Sogari, Velez-Argumendo, Gomez, and Mora (2009) found that time was listed as a significant barrier to healthy eating for almost their entire sample. Participants from the study even reported frequently skipping meals due to lack of time (Sogari et al., 2009). Many college students take a full course load and work at least one job, while balancing a social life. On average, $43 \%$ of full-time students 16-24 years old work a job (National Center for Education Statistics, 2017). The researcher for this study may have better addressed time as a barrier by estimating the amount of time each recipe would take and assigning it to the recipe.

Results from the mixed-between ANOVA analysis found there was a statistically significant effect from pretest to posttest for most of the self-efficacy variables evaluated. However, the main effect comparing the two types of interventions found there was not a statistically significant difference in self-efficacy scores between intervention groups. Students who only received the recipe card had the opportunity to learn what these techniques mean and read instructions on how to complete them. The video technology group could view each task being performed in first person. It was because of this that it was predicted that the video 
technology group would excel compared to the recipe card group. One disadvantage to the video technology tool is that it takes much longer to review the resource compared to just reading a recipe card. The weekly videos lasted approximately four to five minutes each. Video marketing research found that videos less than 60 seconds have the highest completion rate (Pell, 2019). It is possible that many of the students received the resource and then went straight to completing the survey without even viewing the resource.

Results from the mixed-between ANOVA comparing self-efficacy for Weeks 1-5 found there was no statistically significant difference between resource groups for Cooking the meal at home and Performing the cooking techniques throughout the weeks. Participants were also evaluated each week on whether they already had the ability to complete the recipe and if they would plan to try completing the recipe at home. Week 1's recipe (homemade salsa) had a high level of self-efficacy and confidence for performing the cooking techniques and a higher report from participants who stated they would complete the recipe at home. This is likely because Week 1's recipe consisted of primarily one technique, and that was slicing and mixing vegetables. Some participants reported cooking (or rather cutting) skill being the primary barrier to completing the recipe, although $94.4 \%$ of participants stated they already had the ability to complete the recipe.

Week 2's recipe of vegetarian chili had the lowest mean self-efficacy scores for Cooking the meal (4.03) and Performing the cooking techniques at home (4.10). While the recipe itself did not involve many preparation steps, it did consist of using the stovetop to prepare the recipe. Use of the stovetop may have been a significant contributor to the low self-efficacy scores. Only $45.1 \%$ of participants reported that they would try to complete the recipe at home. From the qualitative data it was determined that the researcher's use of several herbs and spices was the 
main reason that participants were not likely to complete the recipe at home. Students reported that the number of ingredients was too expensive for a one-time use. Self-efficacy results and participant plans to complete the recipe may have increased if the researcher had considered convenience of ingredients and used a premade chili mix instead of so many separate spices.

The Week 3 recipe of a kale salad with homemade vinaigrette had the highest confidence of Cooking the meal at home (4.55) and Performing the cooking techniques at home (4.56). Again, this recipe had no actual cooking involved, just chopping and mixing ingredients. While $100 \%$ of participants reported they had the ability to perform the cooking techniques, only $45.1 \%$ of participants planned to actually complete the recipe. A primary reason for this was that the researcher used kale as the leafy green base for the salad. Several participants reported the use of kale as a barrier due to them disliking the ingredients used. The use of a different and neutral leafy green would have been more beneficial.

Week 4's recipe had moderately high confidence for Cooking the meal at home (4.31) and Performing the cooking techniques at home (4.52). Additionally, $71.8 \%$ of participants reported they would plan to try completing the recipe. The participants that reported barriers to completing this recipe reported equipment being the most frequent barrier. The recipe required a masher tool, loaf pan, and a grater to complete the recipe. Without this equipment, participants would be unable to complete the recipe. So while participants felt they had the ability to complete the recipe, they lacked the equipment to do so.

Lastly, Week 5's recipe was a no-mayo and avocado-based chicken salad. Participants were very confident in their self-efficacy for cooking this meal at home (4.37), and performing the cooking techniques (4.35), but only $49.3 \%$ of participants stated they would try completing 
the recipe. Disliking ingredients was the most frequently cited barrier for Week 5. Participants reported feeling confident in the recipe but disliking the use of halved grapes and avocado.

Although the cooking interventions did improve participant self-efficacy for cooking, there were some limitations to the study. The first limitation was related to accountability for participants actually reviewing the resource. Participants could review the resource on their own time, but the researcher could never confirm the participants actually viewed the resource they were assigned. This may have influenced the results because the participants may have skipped their resource and rapidly completed the survey so that they could collect their compensation. This limitation could likely not be resolved in this case because the study design was created so that resources and evaluations could only be accessed digitally.

A second limitation to the study was the researcher's use of certain pieces of equipment to complete the recipes. This greatly affected the results for Week 4's recipe (Zucchini Banana Bread) because participants required a grater, mashing tool, and loaf pan to complete the recipe. The researcher should have considered the equipment availability of the participants or provided alternate options. A third limitation to the study was related to some of the ingredients chosen by the researcher. Particularly on recipes like Vegetarian Chili, the use of too many ingredients greatly inhibited the participant's self-efficacy to complete that recipe due to the overwhelming amount of ingredients. However, this is an important lesson for health educators and dietitians to consider when creating recipes, cooking videos, or cooking interventions for college students. Lastly, after the study it was discovered that five participants had allergies, intolerances, or chose not to eat certain ingredients used. While the initial survey (Appendix B) specifically evaluated and excluded participants that had food allergies, intolerances, sensitivities, or specific dietary 
preferences, some of the participants were not truthful on the question. Results from these participants were kept in the analysis for the sake of transparency of barriers to cooking.

This research is applicable to health educators and dietitians who are responsible for creating and implementing interventions targeting healthy behaviors, obesity, and risk for chronic disease. Through the results of this study, practitioners can create more effective interventions using the variety of resources they have access to, and will better consider the needs of the adolescents and young adults of the next generation.

Based on results of the study, there are several recommendations for future research. Firstly, some of the limitations outlined in this study should be minimized in a revised version. An additional recommendation for future research is to focus on participant accountability when conducting interventions that require non-traditional teaching or technology. Future studies should also try and create an objective procedure of evaluating participant cooking skill. Research that uses recipes should focus on making recipes as simple as possible considering cost per recipe, student access to ingredients, equipment accessibility, and amount of time each recipe takes to complete. Lastly, the incorporation of nutrition education with a cooking skill intervention may provide supportive motivators for students to improve self-efficacy and frequency of cooking meals at home. Several other studies have used and suggested nutrition education as a helpful addition to cooking interventions and improving self-efficacy for healthy eating (Lynette, Agnes Xiao, Gary, \& Audrey Siok, 2017; Strawson et al., 2013).

There are several conclusions that can be drawn from this study. The first conclusion is that regular exposure to some type of cooking educational resource is beneficial to college students' self-efficacy for cooking. Students from the study had statistically significant improvements in self-efficacy for cooking from pretest to posttest. Other studies have noted the 
correlation between self-efficacy for cooking and provision of a cooking resource (Bernardo et al., 2017). While this correlation exists, it is unclear if a cooking video or recipe card is more effective at improving cooking self-efficacy in college students.

Lastly, a conclusion of the study is that increasing self-efficacy for cooking does not result in increased cooking frequency in students. Participants of the study did have improvements in cooking self-efficacy. However, there was not statistical improvement in Number of meals cooked per week from pretest to posttest. This result found that self-efficacy might likely not be the most motivating factor for increasing cooking frequency. Qualitative results from the study found time and cost to be the most significant barriers preventing students from preparing recipes every week. According to the HBM, perceived barriers are a main construct to the value-expectancy model of behavior change (Glanz, Rimer, \& Viswanath, 2008). Until these barriers are addressed or interventions find a way to support students with these barriers, there will be no change in overall behavior of the population. 


\section{CHAPTER II: EXTENDED REVIEW OF LITERATURE \\ Undergraduate College Students}

Undergraduate college students have been thoroughly studied for the incidence of unhealthy lifestyle behaviors (Henry, Cormier, Hebert, Naquin, \& Wood, 2018). As students transition from adolescence to adulthood, they enter a period for establishing behavior patterns that affect long-term health and risk for chronic disease. Several studies have examined student weight gain freshman year, with most supporting a statistically significant weight gain compared to the general population (Cluskey \& Grobe, 2009; Mihalopoulos, Auinger, \& Klein, 2008; Morrow et al., 2006; Vella-Zarb \& Elgar, 2009). The prevalence of overweight and obesity in college students has also become a concern. The ACHA Spring 2019 undergraduate summary reported that only $52.5 \%$ of college students have a Body Mass Index (BMI) described as "healthy" (ACHA, 2019). This prevalence of unhealthy weight in college students may be explained by decreasing levels of physical activity, misconceptions about healthful eating, stress, and the social influences college students are exposed to (Trockel, Barnes, \& Egget, 2000; Pelletier, Lytle, \& Laska, 2016). When asked to describe their weight, $0.9 \%$ of students reported feeling very underweight, $9.3 \%$ reported being slightly underweight, $51.8 \%$ of students felt they were at the right weight, $32.1 \%$ reported being slightly overweight, and $5.9 \%$ reported feeling very overweight (ACHA, 2019).

An additional concern is the number of college students that likely have little to no information about their biochemical health and its ties to risk for disease later in life. In a health assessment of undergraduate college students, Kruger, Roeder, Brubraker, and Kenneth (2014) found that $73 \%$ of the student population had one risk factor for cardiovascular disease (CVD) and 15\% had two or more risk factors for CVD. The ACHA Spring 2019 Undergraduate Report 
found that only $3.6 \%$ of college students consumed five or more servings of fruits and vegetables per day (ACHA, 2019). This means that only 3.6\% of college students meet the USDA 20152020 Dietary Guidelines recommended for adults 19-30 years old (USDA, 2015). While accidental injuries, cancer, and homicide are the leading causes of death in college students, the number of dietary related deaths per year globally is one in five (Turner, Leno, Keller, 2013; GBD Risk Factor Collaborators, 2018). Additionally, Huang et al., (2003), found that only $32.9 \%$ of college students consumed more than 20 grams of fiber per day, compared to the current Dietary Guidelines for Americans of 28 grams per day for women and 33.6 grams per day for men between the ages of 19-30 years old (Huang et al., 2003; USDA, 2015).

With rising levels of attendance to colleges and universities in the United States, there is a greater need for more apartment or residence type housing for undergraduate students (NCHS, 2018; Ong, et al., 2013). This places additional stress on students who must find a way to balance decisions around basic housing, nutritional, and educational expenses. Many students report planning to move off campus because they placed greater importance on cooking at home, having housing access over summer break, private bathroom access, parking availability, cost of housing, and ability to have a private room (Wode, 2018). Additionally, Small, et al., (2012) found that students living off-campus consumed fruits and vegetables $7 \%$ less and were physically active $21 \%$ fewer days compared to students living on campus. Students living on campus are also less likely to drink heavily and engage in sexual activity than are students living off campus (Harford, Wechsler, \& Muthen, 2002; Page, \& O'Hegarty, 2006). However, this does not apply to students living at home with parents who have lower rates of alcohol consumption, cigarette smoking, and marijuana use compared to students living on campus (Long, 2015). 
Past research has demonstrated academic benefits to living on campus rather than off campus or in a Greek organization, ranging from better grades to greater critical thinking skills (Long, 2014). An objective goal to measure college student academic achievement is through Grade Point Average (GPA) reports. Correlations between healthy behaviors and GPA have been thoroughly studied in undergraduate college students. Health behaviors that potentially affect college student GPA include: exercise, sleep, nutrition, social support systems, and stressmanagement techniques. Trockel et al. (2000) found that sleep quality has the most significant influence on student GPAs with the only nutritional variable to have an influence was eating breakfast. Henry et al. (2018) found that anxiety and stress, financial difficulties, lack of sleep, social concerns, attention deficit hyperactivity disorder, computer or video games use, and acute illness had the greatest effect on academic achievement.

\section{Nutrition Education}

Lack of exposure to nutrition education could be a potential explanation for college students' poor dietary habits. Yahia, Brown, Rapley, and Chung (2016) found that students with greater nutrition knowledge had significantly lower intake of fat and cholesterol in their diet, and students who consumed more than $35 \%$ of calories from fat had lower mean nutrition knowledge scores than those with lower fat or cholesterol intake. A separate study found that students who received a web-based intervention designed to improve knowledge of dietary intake successfully increased self-regulatory strategies and self-efficacy for increasing dairy consumption (Poddar, Hosig, Anderson, Nickolas-Richardson, \& Duncan, 2010).

The ACHA’s Spring 2019 National College Health Assessment Undergraduate Report found that only $51.6 \%$ of college students had ever received nutrition information or resources from their college or university (ACHA, 2019). In a study exploring the source of college 
students' nutrition education, $47.6 \%$ reported obtaining information from a health professional, $65.0 \%$ reported their family as the primary source, $52.3 \%$ used their friends, $71.3 \%$ used the Internet, and 50.0\% reported using magazines for their nutrition education (Hertzler \& Bruce, 2002). It can be inferred from this study that most students are not receiving adequate education on healthy eating habits. Additionaly, Brown, O'Connor, and Savaiano (2014) found that only $20 \%$ of baseline respondents from their study had ever heard of or seen the USDA's nutrition education MyPlate model, a tool depicting a plate with all five food groups. Subjects who reported using the MyPlate model had better quality diets than those who did not use the model and had significantly lower energy intake, servings of refined grains or sugar, and consumed more servings of dark green and leafy vegetables (Schwartz \& Vernarelli, 2019). Another costeffective tool used in obesity interventions is education about nutrition fact labels displayed on food products. In the US population, use of nutrition fact labels has been related to healthier food choices (Campos, Doxey, \& Hammond, 2011). In a survey of young adults, one-third used nutrition facts "frequently", and nutrition fact label users consumed more fruits, vegetables, and whole-grains compared to non-users (Christoph, Larson, Laska, Neumark-Sztainer, 2018).

With the accessibility to technology today, nutrition education can be taught in many different forms. Past literature has shown both face-to-face and online education can engage students and increase nutrition knowledge (Adam, Young-Wolf, Konar, \& Winkleby, 2015). While face-to-face educational sessions could likely yield greater improvement in knowledge, online education may provide a more cost-effective approach for improving dietary behaviors. Online courses address many logistical barriers to access nutrition education classes and culinary classes. Several studies have found that using nutrition education in combination with cooking demonstrations can improve diet quality in a variety of populations, with other studies suggesting 
that nutrition education alone may not improve overall diet quality in a population of adolescent students (Lynette et al., 2017; Strawson et al., 2013; Adam et al., 2015). In a study combining nutrition education with cooking interventions, adults who attended the majority of classes showed statistical improvements in total calories and calories from fat (Shankar, et al., 2007).

\section{Cooking Skill and Health}

Cooking as a skill has become increasingly devalued with the ease of using processed foods to provide adequate calories. Time spent on cooking in the United States declined by almost 40\% from 1965-1995 (Jabs, \& Devine, 2006). The 2007-2008 National Health and Nutrition Examination Survey found that 8\% of Americans never cooked dinner in the home, $43 \%$ cooked dinner in the home two to five days per week, and $49 \%$ cooked dinner in the home six to seven days per week (Virudachalam, Long, Harhay, Polsky, \& Feudtner, 2013). More specific to developing students' life skills, high-school courses such as home economics (family

and consumer sciences) and food science are rarely taught or schools have opted out of teaching the subject (Deaton, Carter, \& Daughtery, 2018). Student enrollment in family and consumer science courses during the 2010-2011 and 2011-2012 academic years was under 3.5 million, indicating a decrease in enrollment by $38 \%$ in a decade (Werhan, 2013).

Cooking food at home can be a complex behavior that requires a sequence of steps from planning, obtaining, and preparing a meal. Public health practitioners assume that fast, takeaway, and convenience foods are more likely to be unhealthy choices than cooking from raw ingredients (scratch) in the home (Begley, 2016). These findings demonstrate that preparing food at home is potentially one of the most significant points for effective intervention in curbing the obesity epidemic. Individuals with poorer cooking skills are less likely to cook in the home and are more likely to make poorer food choices that may impact health in areas such as obesity and 
chronic disease (Begley, 2016). In comparison to households that cooked meals one to two times per week, households with moderate-higher frequency (two to five days/week) of cooking in the home consumed significantly lower amounts of calories, fewer grams of carbohydrates and sugar, and ate more fiber (Wolfson \& Bleich, 2015). A cross-sectional study found that families that ate at least one dinner a week away from home had higher odds of overweight/obesity. Mean percent body-fat, insulin levels, and metabolic risk were significantly greater with weekly family purchases from a fast-food restaurant (Fulkerson et al., 2011). It can thus be inferred that when a member of the household cooks dinner in the home, diet quality improves (Virudachalam et al., 2013; Fulkerson et al., 2011).

Many college students entering their first year are bound to dorm-style living and dining hall meals. This is not very different from living at home where parents were the main providers and cooks. Many students are allowed to seek non-dorm housing after their first year at college. This shift from dorm-style housing to apartment-style provides students with the challenge of planning, buying, and preparing their own meals at home. Henry et al. (2018) reported that students living with their parents more often reported eating two or more fruits on five or more days (20.7\%) than did those who lived in off-campus housing (17.8\%), or on campus (3.9\%).

Several studies that have focused on the effect of cooking interventions on university students' dietary habits infer that lack of culinary and basic nutritional knowledge combined with ease of convenience foods may limit control leading to the development of unhealthy eating habits (Strawson et al., 2013; Franciscy, McArthur, \& Holbert, 2004; Soliah, Walter, \& Antosh, 2006; Murray et al., 2016). In addition to observed lack of cooking skill, students also report time as being a significant barrier preventing them from cooking in the home (Escoto, Laska, Larson, Neumark-Sztainer, \& Hannan, 2012). 


\section{Cost of Cooking at Home}

College students commonly cite cost as being a significant barrier preventing them from cooking at home. However, cooking at home may be a more budget-friendly option. Tiwari, Aggarwal, Tang, and Drewnowski (2017) found that frequent home cooking was associated with lower per capita food expenditures $(\$ 330 /$ month among low versus $\$ 270 /$ month among high cooking group). Tiwari et al. concluded, "Cooking dinners at home may be an effective strategy to reduce the consumption of empty calories, and improve diet quality within the budget" (p. 620). The ideology that eating healthy is more expensive is not entirely incorrect. At fast food restaurants, there is a significant inverse relationship between energy density and energy cost (Wellard, Havill, Hughes, Watson, \& Chapman, 2015). This places pressure on families and individuals who are on a budget because they are more inclined to purchase the higher-calorie, but cheaper item.

There are two ways to maximize food dollars, cooking at home or obtaining cheap food outside of the home. Cooking allows limited food dollars to be stretched further in a household of low socioeconomic status (SES). However, poorer, less educated households are more likely to either always or never cook dinner at home, and wealthier, more educated families are more likely to cook dinner at home (Virudachalam et al., 2013).

\section{Health Belief Model (HBM)}

Rosenstock (1974) attributed the first health belief model (HBM) research to Hochbaum's (1958) studies of the uptake of tuberculosis X-ray screening (Abraham \& Sheeran, 2007). HBM is a tool used in public health practice as a value-expectancy model. This means that behavior change will only occur when sufficient benefits remain after subtracting the costs incurred by performing the behavior. There are six constructs to the HBM: (1) Perceived 
susceptibility; (2) Perceived severity; (3) Perceived benefits; (4) Perceived barriers; (5) Selfefficacy; and (6) Cues to action (Janz \& Becker, 1984; Rosenstock, Strecher, \& Becker, 1988). Perceived susceptibility refers to an individual's belief about the likelihood of developing a disease or condition (Glanz et al., 2008). For example, a college student must believe there is a possibility of developing a sexually transmitted infection before they will be interested in being tested for it. Perceived severity refers to an individual's feelings or level of seriousness of contracting an illness and how that illness would influence their health and the possible social consequences (such as effects on work, family, and social relationships) associated with it (Glanz et al., 2008).

An individual must also be able to see the perceived benefits to behavior change such as improved health, financial savings, or other extrinsic rewards that are associated with behavior change (Glanz et al., 2008). Perceived barriers, or the negative aspects of the behavior change, may also act as impediments to adopting a new behavior (Glanz et al., 2008). These individuals must use the value-expectancy model to weigh the tangible and psychological costs of adopting a new behavior against the anticipated benefits. Cues to action are particular messages, resources, and events that instigate action to adopt a new behavior (Glanz et al., 2008). Messages like campaigns for mammograms for women, resources such as free HIV testing, and certain changes in health or events are all examples of cues to action.

The final construct, self-efficacy, refers to an individual's level of competence to overcome perceived barriers to take action (Glanz et al., 2008). While the first four constructs have been developed and researched over the years, self-efficacy and cues to action constructs have rarely been tested (Carpenter, 2010). The majority of college students are young, and thus are less likely to realize their own mortality, health status, or have understanding of the physical 
toll unhealthy behaviors have on the body. In HBM, the likelihood of action is determined by the perceived gains that one believes they will acquire by performing the healthy behavior. For college students, they have the understanding that they should engage in healthy habits, but struggle with overcoming the barriers to change behaviors. In a study evaluating undergraduate students' perceived barriers to healthy eating, the top three barriers were lack of time, unhealthy snacking, and convenience of high-calorie foods (Sogari, et al., 2018). When asked about motivators to preparing meals in the home, college students reported the desire to save money, had a model in food preparation, were familiar with the techniques, and had enough time to shop, cook, and clean up after meals (Jones, Walter, Soliah, \& Phifer, 2014). LaBrosse and Albrecht (2013) used HBM to improve knowledge, self-efficacy, and perceived susceptibility for eating foods dense in folate, an essential vitamin for the body.

\section{Self-Efficacy}

Originally theorized by Albert Bandura (1977), self-efficacy refers to one's belief that they are capable of carrying out the actions necessary for completing a specific behavior (Maddux, 1995). Vicarious experience, a method of self-efficacy, states that self-efficacy can be improved by watching others perform a specific behavior (DiClemente, Salazar, \& Crosby, 2013). Vicarious experience is especially influential on self-efficacy when someone is unsure of his or her ability to perform that behavior (DiClemente, Salazar, \& Crosby, 2013). By observing others perform the same behavior, self-efficacy is improved through the realization that the task itself is not that difficult. In a study exploring the effect of peer modeling of physical activity, participants reported relating to peers as "real people" and "it is doable" perceiving the intervention favorably (Rowland, et al., 2018). 
In a qualitative study of university students, Murray et al. (2016) reported that nutrition knowledge, personal motivations, personal resources, and culinary self-efficacy were all barriers that influenced cooking patterns in the home. Obesity researchers have examined the influence of culinary teaching programs on self-efficacy in college students. Prior studies have examined the ideal length of an intervention targeting self-efficacy. Specifically, in an intervention assessing effect of a text-message intervention on intuitive eating, self-efficacy, and perceived stress, a study found no improvements in general self-efficacy due to the intervention length of five weeks (Loughran, Harpel, Vollmer, \& Schumacher, 2018). While other studies have shown successful improvements in self-efficacy when interventions last up to six months (Annesi, \& Gorjala, 2010). Warmin (2009) found that self-efficacy improved after six weeks of a cooking class taught by a chef. However, no studies have explored using video technology exclusively to improve the self-efficacy of college students for cooking healthy meals. Video technology could be a more effective method in improving self-efficacy for cooking in larger populations since most students are unable to attend cooking classes.

\section{Technology}

Technology today plays a significant role in education in terms of its integration into traditional classes. A 2019 study found that $96 \%$ percent of $18-29$ year olds own a smart phone (Pew Research Center, 2019). Today's average undergraduate student is more than likely born between 1980-2000, placing them in the category known as the Millennial generation (Raines, 2003). Since Millennials were raised always having technology available, they are known as the digital natives. Digital natives are defined as individuals born after 1980 who were raised being surrounded by technology and who possess technological skills unlike any prior generation (Palfrey \& Gasser, 2010; Prensky, 2001). Generally, digital natives prefer media enhanced with 
graphics compared to media consisting only of text (Teo et al., 2014). Because these individuals are more familiar with technology and already have it integrated into their daily lives, technological learning appears to be a relevant tool in teaching and learning in higher education, particularly in the changing face of higher education (Teri et al., 2013). Education with the use of technology has been classified into three categories: First generation interventions use computers to tailor printed materials; second generation interventions use interactive technology delivered on computers; and the third generation interventions use portable devices such as mobile phones for learning and feedback (Neville, O’Hara, \& Milat, 2009).

Mobile applications (also known as apps) are small programs that can be accessed or downloaded onto mobile devices such as smart phones. College students on average enter their primary social media apps up to 11 times per day (Jesse, 2015). Chen (2013) researched education versus non-education application (app) usage among college students. The study found that $58 \%$ of college students used their mobile device for academic and educational purposes (Chen, 2013). An advantage of mobile devices is that users can easily and rapidly access their technology in seconds.

Several common themes emerge from the use of technology or mobile learning. Technology provides the opportunity for a learner-centered and flexible learning environment that allows them to construct knowledge, develop skill training, and be able to receive support in a variety of situations and contexts (Teri et al., 2013). Mobile technology and mobile apps have been used in several different contexts, including language education, business education, and employee training programs (Parr, Jones, \& Songer, 2004; Price et al., 2012; Chen, Kao, \& Sheu, 2003; Huang, Lin, \& Cheng, 2010). 
Video-based learning (VBL) is the instructional process of obtaining information, knowledge, and skills, along with the principled support of video resources (Albó, HernandezLeo, Barcelo \& Sanabria, 2015). Video modeling (VM) uses short video clips to teach selected skills and behaviors to learners one-step at a time. Video promoting (VP), a form of VM, has been used to teach skills such as cooking, cleaning, and dressing. Studies have utilized small screens such as iPods, handheld computers, and larger screen devices for teaching. Regardless of the differences in tasks and materials, VP has been found to effective in teaching independent living skills (Kellems, et al., 2016). Adam et al. (2015) used video technology to increase to teach global participants about nutrition education and cooking techniques. As a result of the study, participants who cooked 5-7 times per week rose from $63.4 \%$ to $71.4 \%$, consumption of fresh vegetables ( $71.4 \%$ to $77.3 \%)$ and fresh fruits (28.4\% to $34.2 \%)$ also increased (Adams et al, 2015). 


\section{REFERENCES}

Abraham, C., \& Sheeran, P. (2007). The health belief model. In S. Ayers, A. Baum, C.

McManus, S. Newman, K. Wallston, J. Weinman, et al. (Eds.) Cambridge Handbook of Psychology, Health and Medicine. Cambridge: Cambridge University Press. doi:10.0117/CBO9780511543579.022

Adam, M., Young-Wolf, K. C., Konar, E., Winkleby, M. (2015). Massive open online nutrition and cooking course for improved eating behaviors and meal composition. The International Journal of Behavioral Nutrition and Physical Activity, 12, 1-9. doi:10.1186/s12966-015-0305-2

Albó P, L., Hernández-Leo, D., Barceló, J., \& Sanabria R. L. (2015). Video-based learning in higher education: The flipped or the hands-on classroom? European Distance and ELearning Network, Retrieved from https://www.openaire.eu/search/publication ?articleId=dedup_wf_001::46b26f34afb9d084a9e9d74fe20a2be0

American College Health Association. (2019). National college health assessment II: Undergraduate student reference group data report spring 2019. Retrieved from https://www.acha.org/documents/ncha/NCHA-I

I_SPRING_2019_UNDERGRADUATE_REFERENCE_GROUP_DATA_REPORT.pdf

Annesi, J., \& Gorjala, S. (2010). Relations of self-regulation and self-efficacy for exercise and eating and BMI change: A field investigation. Biopsychosocial Medicine, 4(1), 10. doi:10.1186/1751-0759-4-10

Begley, A. (2016). Are cooking skills essential to improving public health? Nutridate, 27(1), 3. Retrieved from http://libproxy.lib.ilstu.edu/login?url=https://search.ebscohost. $\operatorname{com} /=\operatorname{loginasp} \mathrm{x}$ direct $=$ true $\& \mathrm{db}=\mathrm{f} 5 \mathrm{~h} \& \mathrm{AN}=113619368 \&$ site $=$ eds-live $\&$ scope $=$ site 
Beheshiti, M., Taspolat, A., Kaya, S. O., \& Sapanca, F.H. (2018). Characteristics of instructional videos. World Journal on Educational Technology: Current Issues, 10(1), 61-69. Retrieved from http://libproxy.lib.ilstu.edu/login?url=https://search./ ebscohost.com/login.aspx?direct=true \&db=eric\&AN=EJ1170366\&site=edslive \&scope $=$ site

Bernardo, G. L., Jomori, M. M., Fernandes, A. C., Colussi, C. F., Condrasky, M. D., Costa Proença, R. P. (2017). Nutrition and culinary in the kitchen program: A randomized controlled intervention to promote cooking skills and healthy eating in university students. Nutrition Journal, 16(83), 1-12. doi:10.1186/s12937-017-0305-y

Brown, O. N., O'Connor, L. E., \& Savaiano, D. (2014). Mobile MyPlate: A pilot study using text messaging to provide nutrition education and promote better dietary choices in college students. Journal of American College Health, 62(5), 320-327, Retrieved from https://doi.org/10.1080/07448481.2014.899233

Campos, S., Doxey, J. \& Hammond, D. (2011). Nutrition labels on pre-packaged food: A systematic review. Public Health Nutrition, 14(8), 1496-1506. doi:10.1017/S1368980010003290

Carpenter, C. J. (2010). A meta-analysis of the effectiveness of health belief model variables in predicting behavior. Health Communication, 25(8), 661-669. doi:10.1080/10410236.2010.521906

Chen, Y. S., Kao, T. C., \& Sheu, J. P. (2003) A mobile learning system for scaffolding bird watching learning. Journal of Computer Assisted Technology. 19, 347-359. Retrieved from https://ieeexplore.ieee.org/document/1039216 
Christoph, M. J., Larson, N., Laska, M. N., \& Neumark-Sztainer, D. (2018). Nutrition facts panels: Who uses them, what do they use, and how does use relate to dietary intake? Journal of the Academy of Nutrition and Dietetics, 118(2), 217-228 doi:10.1016/j.jand.2017.10.014

Cluskey, M., \& Grobe, D. (2009). College weight gain and behavior transitions: Male and female differences. Journal of the American Dietetic Association, 109(2), 325-329. Retrieved from https://www.sciencedirect.com/science/article/pii/S0002822308020385?via\%3Dihub

Deaton, S., Carter, V., \& Daugherty, M. K. (2018). Getting back to the roots of family and consumer sciences education: FCS and STEM integration. Journal of Family and Consumer Sciences, 110(1), 55-58. Retrieved from http://libproxy.lib.ilstu.edu/ login?url=https://search.ebscohost.com/login.asx?direct=true $\& \mathrm{db}=$ eric $\& A N=\mathrm{EJ} 117$ 6148\&site=edslive\&scope=site http://www.ingentaconnect.com/content/aafcs/jfcs

DiClemente, R. J., Salazar, L. F., \& Crosby, R. A. (2013). Health behavior theory for public health: Principles, foundations, and applications. Burlington, MA: Jones and Bartlett Learning

El-Sayed, R. E. \& El-Sayed, S.E. (2013). Video-based lectures: an emerging paradigm for teaching human anatomy and physiology to student nurses. Alexandria Journal of medicine, 3, 215.

Escoto, K. H., Laska, M. N., Larson, N., Neumark-Sztainer, D., \& Hannan, P. J. (2012). Work hours and perceived time barriers to healthful eating among young adults. American Journal of Health Behavior, 36(6), 786. doi:10.5993/AJHB.36.6.6 
Francisney, D. M., McArthur, L. H., \& Holbert, D. (2004). College men and their interest in food purchasing and preparation. Journal of Family and Consumer Sciences, 96(2), 28-33.

Fulkerson, J. A., Farbakhsh, K., Lytle, L., Hearst, M. O., Dengel, D. R., Pasch, K. E., \& Kubik, M. Y. (2011). Away-from-home family dinner sources and associations with weight status, body composition, and related biomarkers of chronic disease among adolescents and their parents. Academy of Nutrition and Dietetics, 111(12), 1892-1897.

Retrieved from https://doi.org/10.1016/j.jada.2011.09.035

GBD Risk Factor Collaborators (2018). Global, regional, and national comparative risk assessment of 84 behavioral, environmental and occupational, and metabolic risks or clusters of risks for 195 countries and territories, 1990-2017: A systematic analysis for the Global Burden of Disease Study 2017. Lancet (London, England), 392(10159), 19231994. doi:10.1016/S0140-6736(18)32225-6

Glanz, K., Rimer, B. K., \& Viswanath, K. (Eds.) (2008). Health Behavior and Health Education. San Francisco, CA: John Wiley \& Sons.

Harford, T. C., Wechsler, H., \& Muthen, B. O. (2002). The impact of current residence and high school drinking on alcohol problems among college students. Journal of Studies on Alcohol, 63(3), 271. doi:10.15288/jsa.2002.63.271

Henry, B., Cormier, C., Hebert, E., Naquin, M., \& Wood, R. (2018). Health and health care issues among upper-level college students and relationships to age, race, gender, and living arrangements. College Student Journal, 52(1), 7-20. Retrieved from http://libproxy.lib.ilstu.edu/login?url=https://search.ebscohost.com/login.aspx?dir ect $=$ true $\& \mathrm{db}=$ edsbl\&AN=RN616126359\&site=eds-live \&scope=site 
Hertzler, A. A. \& Bruce, F. A. (2002). Cooking, recipe use, and food habits of college students and nutrition educators. International Journal of Consumer Studies. 26(4), 340-345. doi:10.1046/j.1470-6431.2002.00248.x

Huang, T. T.-K., Harris, K. J., Lee, R. E., Nazir, N., Born, W., \& Kaur, H. (2003). Assessing overweight, obesity, diet, and physical activity in college students. Journal of American College Heatlh, 52(2), 83-86. doi: 10.1080/07448480309595728

Huang, Y., Lin, Y., \& Cheng, S. (2010) Effectiveness of a mobile plant learning system in a science curriculum in Taiwanese elementary education. Computers and Education, 54, 47-58. doi:10.1016/j.compedu.2009.07.006

Jabs, J., \& Devine, C. M. (2006). Time scarcity and food choices: An overview. Appetite, 47(2), 196-204. doi:10.1016/j.appet.2006.02.014

Janz, N. K., \& Becker, M. H. (1984). The health belief model: A decade later. Health Education Quarterly, 11(1), 1-47. doi: 10.1177/109019818401100101

Jesse, G. R. (2015). Smartphone and app usage among college students: Using smartphones effectively for social and educational needs. Information Systems and Computing Academic Professionals, 17(4), 8. Retrieved from http://proc.iscap.info/2015/pdf/3424.pdf

Jones, C. L., Jensen, J. D., Scherr, C. L., Brown, N. R., Christy, K., \& Weaver, J. (2015). The health belief model as an explanatory framework in communication research: Exploring parallel, serial, and moderated mediation. Health Communication, 30(6), 566-576. Retrieved from http://doi.org/10.1080/10410236.2013.873363\ 
Jones, S. A., Walter, J., Soliah, L., \& Phifer, J. T. (2014). Perceived motivators to home food preparation: A focus groups. Journal of the Academy of Nutrition and Dietetics, 114,(10), 1552- 1556. Retrieved from https://dx.doi.org/10.1016/j.jand.2014.05.003

Kellems, R. O., Mourra, K., Morgan, R. L., Riesen, T., Glasgow, M., \& Huddleston, R. (2016). Video modeling and prompting in practice: Teaching cooking skills. Career Development and Transition for Exceptional Individuals, 39(3), 185-190. Retrieved from http://libproxy.lib.ilstu.edu/login?url=https://search.ebscohost.com/login.asp $\mathrm{x} ?$ direct $=$ true $\& \mathrm{db}=$ eric $\& \mathrm{AN}=\mathrm{EJ} 1107687 \&$ site $=$ edslive $\&$ scope $=$ site

Kruger, L. B., Roeder, L. D., \& Brubaker, K. D. (2014). Health assessment data collection as part of a college wellness course. Physical Educator, 71(4), 580-593. Retrieved from http://libproxy.lib.ilstu.edu/login?url=https://search.ebscohost.com/login.asp $\mathrm{x}$ ?direct $=$ true $\& \mathrm{db}=$ eft $\& \mathrm{AN}=99730067 \&$ site $=$ eds-live $\&$ scope $=$ site

LaBrosse, L., \& Albrecht, J. A. (2013). Pilot intervention with adolescents to increase knowledge and consumption of folate-rich foods based on the health belief model. International Journal of Consumer Studies, 37(3), 271-278. doi:10.1111/ijcs.12004

Long, L. D. (2014). Does it matter where college students live? Differences in satisfaction and outcomes as a function of students' living arrangement and gender. The Journal of College and University Student Housing, 40(2), 66-84. Retrieved from https://content.ebscohost.com/ContentServer.asp?T=P\&P=AN\&K=110375362\&S= $\mathrm{R} \& \mathrm{D}=\mathrm{tfh} \&$ EbscoContent $=\mathrm{dGJyMMv17ESep7Y4zOX0OLCmr1GeqLBSsKq4Ta \% 2BWx}$ WXS\&ContentCustomer $=$ dGJyMPGuskmwr7VLuePfgeyx 43zx 
Long, M. B. (2015). Substance use behaviors of college students: Differences by living arrangement. Dissertations, Retrieved from https://pdfs.semanticscholar.org/4f9f/dd9c05f3246eb0d672a7d9714b4aa5a9539d.pdf?_ga $=2.159932660 .810267998 .1574217939-1042254546.1574217939$

Loughran, T. J., Harpel, T., Vollmer, R., \& Schumacher, J. (2010). Effectiveness of intuitive eating intervention through text messaging among college students. College Student Journal, 52(2), 232-244.

Lynette Mei, L. G., Agnes Xiao, Y. W., Gary, Y. A., \& Audrey Siok, L. T. (2017). Effectiveness of nutrition education accompanied by cooking demonstration. British Food Journal, 119(5), 1052-1066. doi:10.1108/BFJ-10-2016-0464

Maddux, J. E. (1995). Self-efficacy adaptation and adjustment: Theory, research, and application. New York, NY: Plenum Press

Mihalopoulos, N. L., Auinger, P., \& Klein, J. D. (2008). The freshman 15: Is it real? Journal of American College Health, 56(5), 531-533. doi: 10.3200/JACH.56.5.531-534

Morrow, M. L., Heesch, K. C., Dinger, M. K., Hull, H. R., Kneehans, A. W., \& Fields, D. A. (2006). Freshman 15: Fact or fiction? Obesity, 14(8), 1438-1443. doi:10.1038/oby.2006.163

Murray, D. W., Mahadevan, M., Gatto, K., O'Connor, K., Fissinger, A., Bailey, D., Cassara, E., \& O'Connor, K. (2016). Culinary efficacy: An exploratory study of skills, confidence, and healthy cooking competencies among university students. Perspectives in Public Health, 136(3), 143-151. doi:10.1177/1757913915600195 
Neville, L. M., O’Hara, B., Milat, A. (2009). Computer-tailored physical activity behavior change interventions targeting adults: A systematic review. The International Journal of Behavior Science, 24(4), 699-720. doi:10.1186/1479-5868-6-30

Ong S. E., Milena, P., \& Spieler, A. C. (2013). Demand for university student housing: An empirical analysis. Journal of Housing Research, 22(2), 141-164. Retrieved from http://libproxy.lib.ilstu.edu/login?url=https://search.ebscohost.com/login.asp $\mathrm{x}$ ?direct $=$ true $\& \mathrm{db}=$ edsjsr\&AN=edsjsr.24862547\&site=eds-live\&scope $=$ site

Page, R. M., \& O’Hegarty, M. (2006). Type of student residence as a factor in college students' alcohol consumption and social normative perceptions regarding alcohol use. Journal of Child and Adolescent Substance Abuse, 15(3), 15-31. doi:10.1300/ J029v15n03_02

Palfrey, J., \& Gasser, U. (2008). Born digital: Understanding the first generation of digital natives. New York, NY: Basic Books.

Parr, C. S., Jones, T., \& Songer, N. B. (2004) Evaluation of a handheld data collection interface for science learning. Journal of Science Education and Technology, 13(2), 233-242. Retrieved from https://search.proquest.com/docview/2259586966?accountid=11578

Pell, S. (2019). Benchmark Report. Vidyard. Retrieved from https://www.vidyard.com/pressreleases/2019-business-video-benchmarks/

Pelletier, J. E., Lytle, L. A., \& Laska, M. N. (2016). Stress, health risk behaviors, and weight status among community college students. Health Education \& Behavior, 43(2), 139144. Retrieved from http://libproxy.lib.ilstu.edu/login?url=https://search.ebscohos t.com/login.asp 2 direct $=$ true $\& d b=$ sph $\& A N=114170604 \&$ site $=$ eds-live $\&$ scope $=$ site 
Peterson, S., Duncan, D. P., Null, D. B., Roth, S. L., \& Gill, L. (2010). Positive changes in perceptions and selections of healthful foods by college students after a short-term point-of-selection intervention at a dining hall. Journal of American College Health, 58(5), 425. doi:10.1080/07448480903540457

Pew Research Center (2019). Mobile fact sheet. Internet and Technology. Retrieved from https://www.pewinternet.org/fact-sheet/mobile/

Poddar, K. H., Hosig, K. W., Anderson, E. S., Nickolas-Richardson, S. M., Duncan, S. E. (2010). Web-based nutrition education intervention improves self-efficacy and selfregulation related to increased dairy intake in college students. Journal of the American Dietetic Association. 11(110), 1723-1727. doi:10.1016/j.jada.2010.08.008

Prensky, M. (2001). Digital natives, digital immigrants. On the Horizon, 9(5), 1-6.

Price, S., Davies, P., Farr, W., Jewitt, C., Roussos, G., \& Sin, G. (2012) Fostering geospatial thinking in science education through a customizable smartphone application. British Journal of Educational Technology, 45(1), 160-170. Retrieved from http://explore.bl.uk/primo_library/libweb/action/display.do?tabs=detailsTab\&gat $\mathrm{hStatTab}=$ true $\& \mathrm{ct}=$ display $\& \mathrm{fn}=$ search $\&$ doc $=\mathrm{ETOCRN} 346263517 \&$ ind $\mathrm{x}=1 \& \mathrm{rec} \mathrm{Ids}=\mathrm{E}$ TOCRN346263517

Raines, C. (2003). Connecting generations: The sourcebook. Seattle, WA: Crisp Publications Rao, S. P., Lozano, V., \& Taani, M. (2014). Cues to healthy decision-making among college students: Results from a pilot study. College Student Journal, 48(4), 697-706. Retrieved from http://libproxy.lib.ilstu.edu/login?url=https://search.ebscohost.com $/$ login.aspx direct $=$ true $\& \mathrm{db}=\mathrm{eft} \& \mathrm{AN}=100358665 \&$ site $=$ eds-live $\&$ scope $=$ site 
Rosenstock, I. M., Strecher, V. J., \& Becker, M. H. (1988). Social learning theory and the health belief model. Health Education Quarterly. 15, 1785-183.

Rowland, S. A., Cohen, M. Z., Pullen, C. H., Schulz, P. S., Berg, K. E., \& Yates, B. C. (2018). Perceptions of a peer modeling workplace physical activity intervention for women. Workplace Health \& Safety, 66(9), 437-443. doi:10.1177/2165079918782258

Schwartz, J. L., \& Vernarelli, J. A. (2019). Assessing the public's comprehension of dietary guidelines: Use of MyPyramid or MyPlate is associated with healthier diets among US adults. Journal of the Academy of Nutrition \& Dietetics, 119(3), 482-489. Retrieved from http://libproxy.lib.ilstu.edu/login?url=https://search.ebscohost.com/login.aspx?direc $\mathrm{t}=$ true $\& \mathrm{db}=$ sph\&AN $=134736964 \&$ site $=$ eds-live $\&$ scope $=$ site $=$

Shankar, S., Klassen, A. C., Garret-Mayer, E., Houts, P. S., Wang, T., McCarthy, M., Cain, R., \& Zhang, L. Evaluation of a nutrition education intervention for women residents of Washington, DC, public housing communities. Health Education Research, 22(3), 425437. doi:10.1093/her/cyl092

Small, M., Bailey-Davis, L., Morgan, N., \& Maggs, J. (2013). Changes in eating and physical activity behaviors across seven semesters of college: Living on or off campus matters. Health Education \& Behavior, 40(4), 435. Retrieved from http://searchebscohost.com/login.aspx?direct=true\&db=edb\&AN=89109375\&site=edslive $\&$ scope $=$ site

Sogari, G., Velez-Argumedo, C., Gómez, M. I., \& Mora, C. (2018). College students and eating habits: A study using an ecological model for healthy behavior. Nutrients, 10, (12), 1823. 
Soliah, L., Walter, J., \& Antosh, D. (2006). Quantifying the impact of food preparation skills among college women. College Student Journal, 40(4), 729. Retrieved from http://libproxy.lib.ilstu.edu/login?url=https://search.ebscohost.com/login.aspx?direct=true $\& \mathrm{db}=$ sph $\& \mathrm{AN}=23588695 \&$ site $=$ ehost-live $\&$ scope $=$ site

Strawson, C., Bell, R., Downs, S., Farmer, A., Olstad, D., \& Willows, N. (2013). Dietary patterns of female university students with nutrition education. Dietitans of Canada, 74(3), 138-142. Retrieved from http://libproxy.lib.ilstu.edu/login?url=https://search.ebscohost.com/login.aspx?direct=true $\& \mathrm{db}=$ edsbl\&AN=RN338820834\&site $=$ eds-live \&scope $=$ site

Surgenor, D., Hollywood, L., Furey, S., Lavelle, F., McGowan, L., Spence, M., \& Dean, M. (2017). The impact of video technology on learning: A cooking skills experiment. Appetite, 114(1), 306-312. doi:10.1016/j.appet.2017.03.037

Teo, T., Kabakçı Yurdakul, I., \& Ursavas , O. F. (2014). Exploring the digital natives among preservice teachers in Turkey: A cross-cultural validation of the Digital Natives Assessment Scale. Interactive Learning Environments, 14(6), 1231-1244. doi:10.1080/10494820.2014.980275

Teri, S., Acai, A., Griffith, D. Mahmoud, Q., Ma, D. W. L., \& Newton, G. (2013). Student use and pedagogical impact of a mobile learning application. Biochemistry and Molecular Biology Education. 42(2) 121-135. doi:10.1002/bmb.20771

Tiwari, A., Aggarwal, A., Tang, W., \& Drewnowski, A. (2017). Cooking at home: A strategy to comply with U.S. dietary guidelines at no extra cost. American journal of preventive medicine, 52(5), 616-624. doi:10.1016/j.amepre.2017.01.01 
Trockel, M. T., Barnes, M. D., \& Egget, D. L. (2000). Health-related variables and academic performance among first-year college students: Implications for sleep and other behaviors. Journal of American College Health, 49,(3),125-131 doi: $10.1080 / 07448480009596294$

Turner, J. C., Leno, E. V., \& Keller, A. (2013). Causes of mortality among American college students: A pilot study. Journal of College Student Psychotherapy, 27(1), 31-42. doi:10.1080/87568225.2013.739022

United States Department of Health and Human Services and U.S. Department of Agriculture. (2015).2015 - 2020 Dietary Guidelines for Americans. Retrieved from https:/health.gov/dietaryguidelines/2015/guidelines/.

United States Department of Housing and Urban Development (2015). Insights into housing and community development policy. Office of Policy Development and Research. Retrieved from https://www.huduser.gov/portal/periodicals/insight/insight_2.pdf

Vella-Zarb, R. A., \& Elgar, F. J. (2009). The "freshman 5": A meta- analysis of weight gain in the freshman year of college. Journal of American College Health, 58(2), 161-166. doi:10.1080/07448480903221392

Virudachalam, S., Long, J. A., Harhay, M. O., Polsky, D. E., \& Feudtner, C. (2013). Prevalence and patterns of cooking dinner at home in the USA: National health and nutrition examination survey 2007-2008. Public Health Nutrition 17(5), 1022-1030. doi: $10.1017 / \mathrm{S} 1368980013002589$ 
Warmin, A. (2009). Cooking with a chef: A culinary nutrition intervention for college aged students. All Theses, 556. Retrieved from https://search-proquest com.libproxy.lib.ilstu.edu/docview/304863216

Warziski, M. T., Sereika, S. M., Styn, M. A., Music, E., \& Burke, L. E. (2008). Changes in selfefficacy and dietary adherence: The impact on weight loss in the PREFER study. Journal of Behavioral Medicine, 31(1), 81-92. doi:10.1007/s10865-007-9135-2

Wellard, L., Havill, M., Hughes, C., Watson, W. L., \& Chapman, K. (2015). Energy-dense fast food products cost less: An observational study of the energy density and energy cost of Australian fast foods. Food and Obesity, 39(6), 544-555. doi:10.1111/1753-6405.12430

Werhan, C. R. (2013) Family and consumer sciences secondary programs: National survey continued demand for FCS teachers. American Association of Family and Consumer Sciences, 105(4), 41-45. Retrieved from https://higherlogicdownload.s3.amazonaws.c om/AAFCS/1c95de14-d78f-40b8-a6ef-a1fb628c68fe/UploadedImages/About/JFCS_1054_Werhan.pdf

Wode, J. (2018). Identifying the factors that motivate students to choose off-campus housing. Journal of College and University Student Housing, 44(2), 44-63. Retrieved from https://content.ebscohost.com/ContentServer.asp?T=P\&P=AN\&K=129992307\&S=R\&D $=$ tfh $\&$ EbscoContent $=\mathrm{dGJyMMv17ESep7Y4zOX0OLCmr1GeqLBSr624TK6WxWXS \& C}$ ontentCustomer=dGJyMPGuskmwr7VLuePfgeyx43zx

Wolfson, J. A., \& Bleich, S. N. (2015). Is cooking at home associated with better diet quality or weight-loss intention? Public Health Nutrition, 18(8), 1397-1406. doi:10.1017/S1368980014001943 
Yahia, N., Brown, C. A., Rapley, M., \& Chung, M. (2016). Level of nutrition knowledge and its association with fat consumption among college students. BMC Public Health, 16,(1), 1-10. doi:10.1186/s12889-016-3728-z 


\section{APPENDIX A: INFORMED CONSENT}

Dear Prospective Participant,

You are invited to participate in a research study evaluating undergraduate college students' confidence in cooking at home. The purpose of this study is to determine the best method for teaching college students about cooking and eating healthy in the home.

To participate you must be 18-25 years old, live off campus (non-dorm housing) without a parent or guardian, have access to a kitchen, and be an undergraduate student of Illinois State University. In addition, you must have access to a computer, laptop, or mobile device that can access the Internet. Your participation in this study will contribute to the body of knowledge relating to cooking habits of college students.

You will be asked to complete a 5-minute survey evaluating your eligibility for the study. After the initial survey, you will be split up into two groups. Each group will be emailed a different cooking resource to review once per week for five weeks. After viewing each cooking resource you will be responsible for completing a short 1-2 minute survey. At the end of the study participants will complete the same survey as before the study.

Participants who complete all surveys will receive a $10 \$$ gift card to Target.

If you are eligible for this study and are interested in participating, please click the link below: https://illinoisstate.az1.qualtrics.com/jfe/form/SV_2o6LKrOIll3zrPT

To learn more about this project, please contact Dr. Julie Schumacher at jmraede@ilstu.edu or 309-438-7031 or Zak Kaesberg at zakaesb@ilstu.edu or

\section{7-621-0117}

Thank you for your time and consideration.

Sincerely, 
Zak Kaesberg 


\section{APPENDIX B: PRE AND POSTTEST SURVEY}

\section{Start of Block: Effects of Video Technology on Cooking Self-Efficacy}

We are inviting you to participate in a research study. Zak Kaesberg, is conducting this study under the supervision of Dr. Julie Schumacher, here at Illinois State University using surveys. The purpose of this study is to evaluate the level of ability for cooking healthy meals in undergraduate university students living off-campus. Study participants must be between the ages of 18 and 25 years old and live in off-campus housing without their parent or guardian. For those who choose to participate, the study requires completion of an initial survey. This survey is 11 questions but the survey may intentionally skip some questions depending on your answers. Therefore, you may end up answering fewer than 11 questions. The survey is estimated to take about five minutes. Based on your responses you will be evaluated on your eligibility for the study. After the initial survey, participants will be asked to review a cooking resource using their computer or smartphone once per week for five weeks. After each resource is given, participants will be asked to complete a short three-question survey. This survey should take one to two minutes. At the end of the five weeks you will be asked to complete the same initial survey as before the study. To receive compensation for this study, participants must complete all administered surveys. Data for this study will be reported as aggregate data removed of all identifiers from the study. The data will be used as for a master's thesis at Illinois State University. The thesis may potentially be submitted to a publication or presented at a research convention. The risks/discomforts in this study are minimal-no greater than those in regular life. Some questions are personal and may be a bit uncomfortable; you may skip any questions that make you feel uncomfortable. Your responses will help determine the best method for 
teaching students about healthy cooking. Upon answering the questions your name and personal information will be removed and you will create a code to identify you throughout the study. For participating in this study, you will be given a $10 \$$ Target gift card to be picked up in the Family, and Consumer Sciences office in Turner Hall 110 one week after completion. The IRS may consider these payments to be taxable compensation. Recipients of a research participant incentive payment may want to consult with their personal tax advisor for advice regarding the participant's situation. Any participant also has the opportunity to participate in the study without accepting the research incentive payment. In order to receive the compensation, at the end of the survey you will be taken to a separate page to enter your contact information. This information will be kept entirely separate from the survey and your responses and will be securely stored by the researcher for audit purposes only. Participation is voluntary, and you can withdraw from the study at any time. You may also withdraw consent at any time. There will be no penalty for refusing to take this survey or withdrawing from it. Please note you are ineligible for this study if you are currently in the European Economic Area.

If you have any questions about this research, you can contact Dr. Julie Schumacher at 309-4387031 or Zak Kaesberg at 217-621-0117.

If you would like to know more about your rights as a participant or want to discuss concerns, you can contact the Research Ethics \& Compliance Office at Illinois State University at (309) 438-5527 or via email at rec@ilstu.edu. 
Please indicate if you understand and consent to the study:

I consent

I do not consent

Skip To: End of Survey If Please indicate if you understand and consent to the study: = I do not consent

Page Break 
Please select your dietary choices:

Plant and Animal Products

Vegetarian (consumes dairy not eggs)

Vegetarian (consumes eggs not dairy)

Vegetarian (consumes dairy and eggs)

Vegan

Pescatarian (consumes fish no meat)

Other:

Please select your status at Illinois State University

Freshman

Sophomore

Junior

Senior

Graduate 
Please select your current residential status:

\section{Dorm}

Apartment-style Housing (with kitchen access)

House (with kitchen access)

Apartment or House (no kitchen access)

Skip To: End of Survey If Please select your current residential status: = Dorm

Skip To: End of Survey If Please select your current residential status: = Apartment or House (no kitchen access)

Do you live with your parent or guardian(s)?

Yes

No

Are you, or have you ever been a cook, chef, or worked in a professional kitchen?

Yes

No 
About how many meals do you cook in the home per week?

$0-2$

$3-5$

6-8

$9-11$

$12-14$

$15+$

Please describe your confidence in:

\begin{tabular}{|c|c|c|c|c|c|}
\hline & Not at all & $\begin{array}{l}\text { Not so } \\
\text { confident }\end{array}$ & $\begin{array}{c}\text { Somewhat } \\
\text { confident }\end{array}$ & $\begin{array}{c}\text { Very } \\
\text { confident }\end{array}$ & $\begin{array}{r}\text { Extremely } \\
\text { confident }\end{array}$ \\
\hline $\begin{array}{c}\text { Cooking at } \\
\text { home: }\end{array}$ & $\bigcirc$ & $\bigcirc$ & $\bigcirc$ & $\bigcirc$ & 0 \\
\hline $\begin{array}{l}\text { Following a } \\
\text { written } \\
\text { recipe: }\end{array}$ & $\bigcirc$ & $\bigcirc$ & $\bigcirc$ & $\bigcirc$ & $\bigcirc$ \\
\hline $\begin{array}{c}\text { Preparing } \\
\text { dinner from } \\
\text { items already } \\
\text { in the } \\
\text { kitchen: }\end{array}$ & $\bigcirc$ & $\bigcirc$ & $\bigcirc$ & 0 & $\bigcirc$ \\
\hline $\begin{array}{l}\text { Cooking from } \\
\text { scratch: }\end{array}$ & $\bigcirc$ & $\bigcirc$ & $\bigcirc$ & 0 & $\bigcirc$ \\
\hline $\begin{array}{l}\text { Planning and } \\
\text { cooking } \\
\text { healthy } \\
\text { meals: }\end{array}$ & $\bigcirc$ & $\bigcirc$ & 0 & $\bigcirc$ & $\bigcirc$ \\
\hline
\end{tabular}


Please describe your confidence in these cooking techniques:

\begin{tabular}{|c|c|c|c|c|c|}
\hline & $\begin{array}{l}\text { Not at all } \\
\text { confident }\end{array}$ & $\begin{array}{l}\text { Not so } \\
\text { confident }\end{array}$ & $\begin{array}{l}\text { Somewhat } \\
\text { confident }\end{array}$ & $\begin{array}{c}\text { Very } \\
\text { confident }\end{array}$ & $\begin{array}{l}\text { Extremely } \\
\text { confident }\end{array}$ \\
\hline Boiling & $\bigcirc$ & 0 & $\bigcirc$ & $\bigcirc$ & $\bigcirc$ \\
\hline Simmering & $\bigcirc$ & 0 & 0 & $\bigcirc$ & $\bigcirc$ \\
\hline Sautéing & 0 & 0 & 0 & $\bigcirc$ & ○ \\
\hline Stir-Frying & O & 0 & $\bigcirc$ & 0 & 0 \\
\hline Grilling & $\bigcirc$ & $\bigcirc$ & $\bigcirc$ & ○ & 0 \\
\hline Baking & O & 0 & 0 & $\bigcirc$ & 0 \\
\hline Roasting & $\bigcirc$ & O & O & $\bigcirc$ & O \\
\hline Microwaving & $\bigcirc$ & $\bigcirc$ & $\bigcirc$ & 0 & 0 \\
\hline
\end{tabular}


Please choose your current marital status:
Single
Married
Separated
Divorced
Widowed

Do you have children?
Yes
No

Skip To: End of Survey If Do you have children? = Yes

Please choose how you identify your gender:
Male
Female
Other 
Please choose your age category:
$18-19$
20-21
$22-23$
24- 25
older than 25

\section{Page Break}

Enter your identifier code:

First letter of your mother's maiden name:

Two digit month you were born $\quad$ (Example-01, 03, 09, 10, 12): (2)

Last two digits of cell phone number: 


\section{APPENDIX C: WEEKLY POST RESOURCE SURVEY}

\section{Start of Block: Default Question Block}

Please complete this survey after reviewing your cooking resource. The survey should take 1-2 minutes to complete.

\section{Page Break}

Describe your level of confidence in:

\begin{tabular}{c|ccccc} 
Not at all & $\begin{array}{c}\text { Not so } \\
\text { confident }\end{array}$ & $\begin{array}{c}\text { Somewhat } \\
\text { confident }\end{array}$ & $\begin{array}{c}\text { Very } \\
\text { confident }\end{array}$ & $\begin{array}{r}\text { Extremely } \\
\text { confident }\end{array}$ \\
\hline $\begin{array}{c}\text { Cooking this } \\
\text { meal at home: }\end{array}$ & 0 & 0 & & \\
$\begin{array}{c}\text { Performing } \\
\text { these cooking } \\
\text { techniques: }\end{array}$ & 0 & 0 & 0 &
\end{tabular}

Are there barriers that would prevent you from preparing this meal? If yes, what are they?

Yes

No 
Do you already have the ability to perform these cooking techniques?
Yes
No

Will you plan to try completing this recipe?

\section{Yes}

No

\section{Page Break}

What is your identifier code? Hint: (First letter of mother's maiden name)(First two digits of month of birth)(Last two digits of cell phone) Example: D0817 